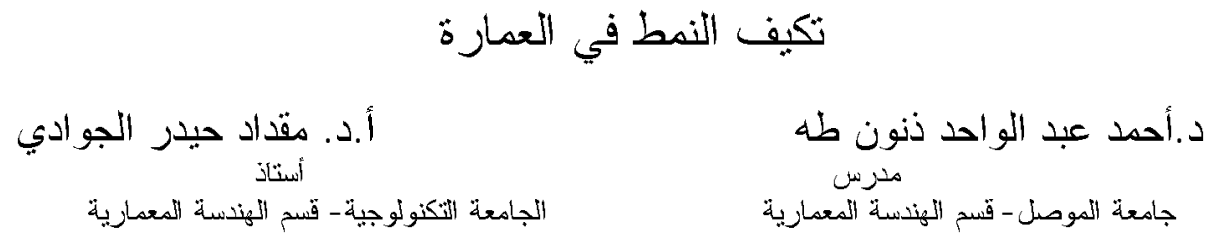

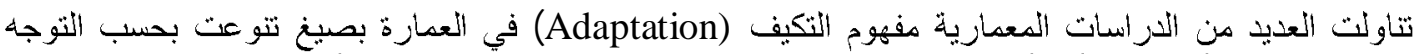

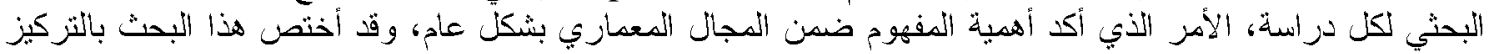

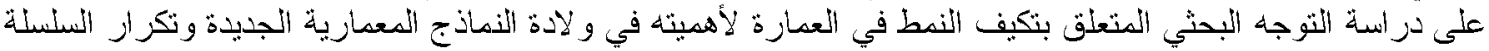

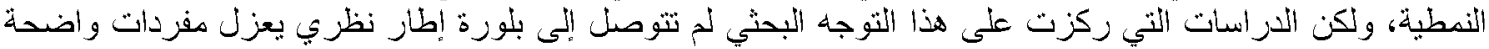

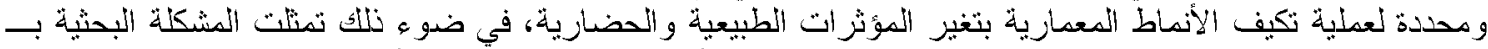

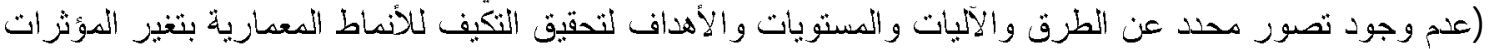

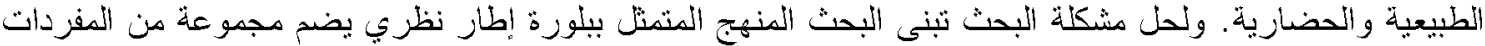

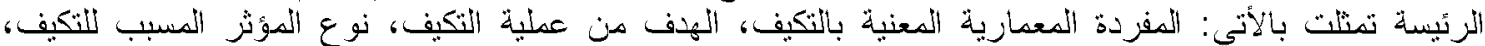

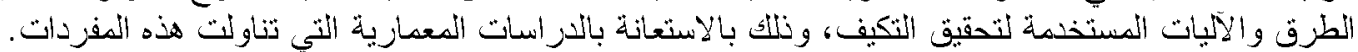

الكلمات الدالة: التكيف، النمط، التحو لات النمطية، التعديل

\title{
The Adaptation of type in Architecture
}

\section{Dr. Ahmad Abdul wahid Thanoon P.Dr. Miqdad Haidar AL-jawadi}

Many Architectural studies deals with concept of adaptation in architecture with different ways various according to the trend of each study, this show's the importance of studying the concept of adaptation in the architectural field in general. This research tray to focus on the concept of the adaptation of type in architecture because it's important in the generation of the new architectural models and the reiteration of the typological chain. Reviewing previous studies focusing on this concept show's the absent of a theoretical frame witch separate a specific items of the process of adaptation of the architectural types through different natural and cultural effects. Thus, the problem her was the absence of a specific imagination of the procedures and mechanisms for achieving adaptation of the architectural types through different natural and cultural effects. To solve this problem, the researcher adopted the approach of building a theoretical framework for the adaptation of type in architecture, Witch includes the items: The target of adaptation, the kind of effect which cues adaptation, the procedures and mechanisms to achieve adaptation. The achievement of these items depended on the help of the previous studies.

Key words: Adaptation, type, Typological Transformation, alteration 


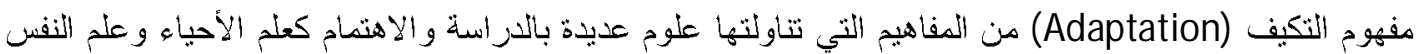

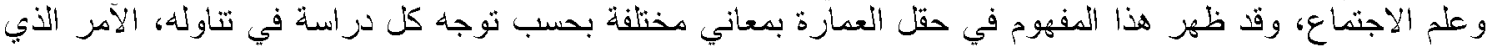

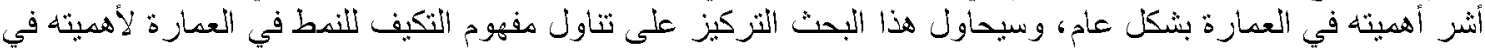

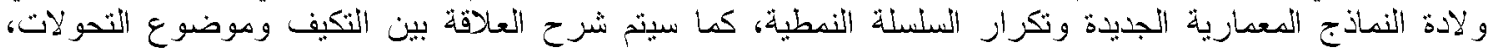

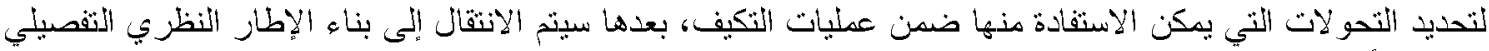
لتكيف الأماط في العمارة.

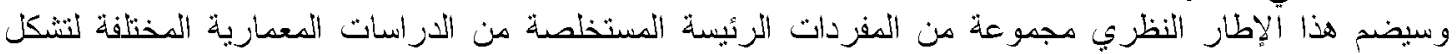

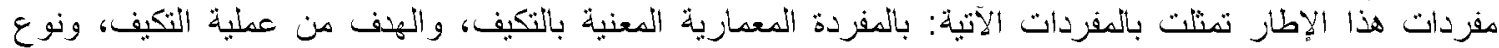
المؤثر المسبب للتكيف، و الطزق و الآليات المستخمة لتحقيق التكيف، وذلك بالاستعانة بالتر أسات المعمارية التي تناولت

هذه ألمفزدات.

2 - التكيف في الدراسات المعمارية:

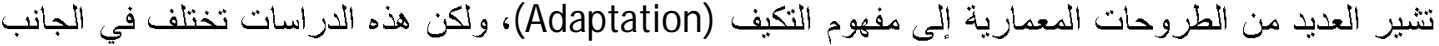

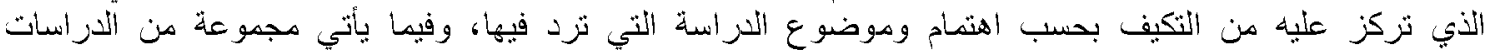

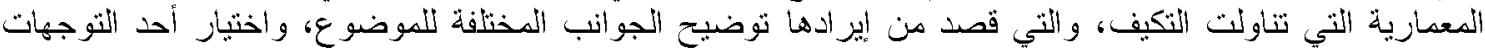

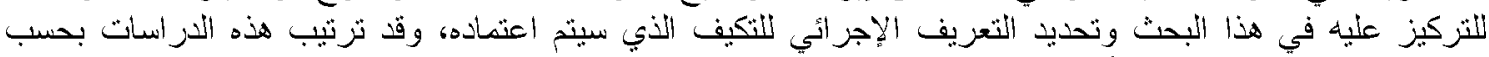
طريقة تناولها للففهوم، وكما يأني:

$$
\text { 1-2 الندراسات التي تناولت التكيف كمغهوم مرتبط بائتحولات الندطية: }
$$

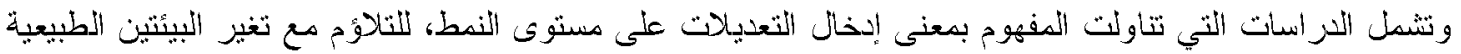

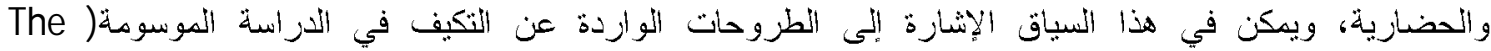
adaptation and Growth of the Bungalow in India)

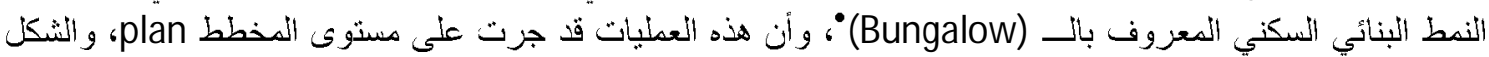

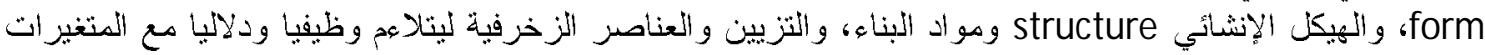

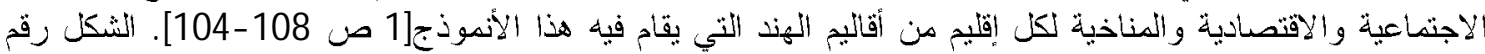

و تتنزج در أسة كزس آيبل (Architecture and Identity Towards a global eco-culture)؛ ضمن السياق

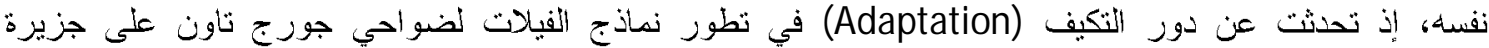

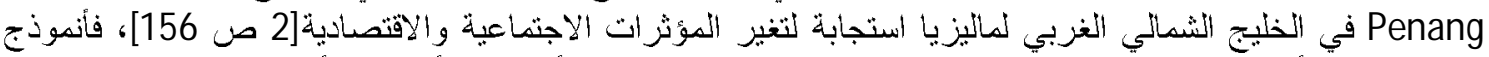

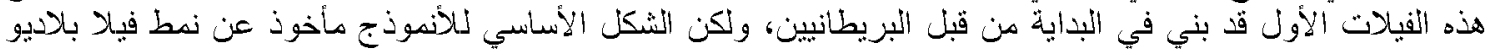

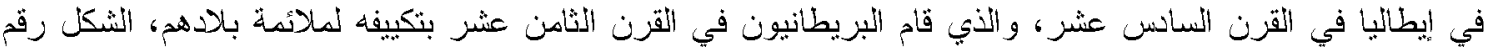

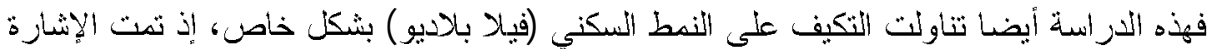

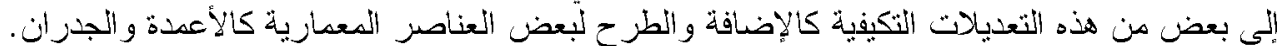

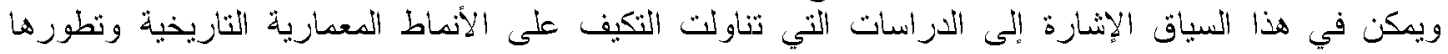

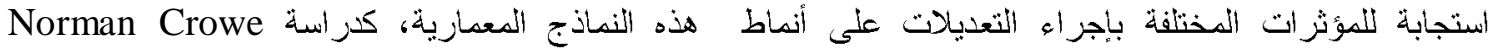
The التي أنشازت إلى نطور أنموذج المعبد النقليدي) (Nature And The Idea Of A Man -Made World) (Classical Temple

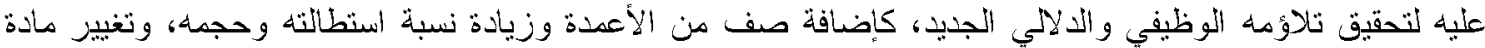

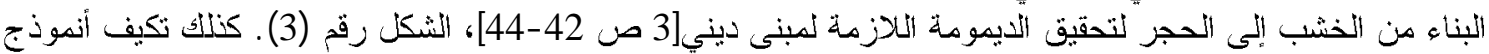

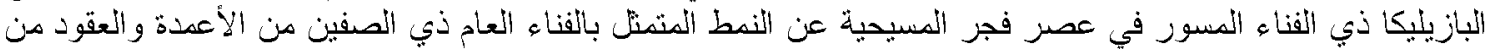

• يقصد به المسكن المتكون من طابق واحد وذو السقف الجملوني، وهو نمط سكني ادخله المستعمر الإنكليزي إلى مناطق وأقاليم المند المختلفة

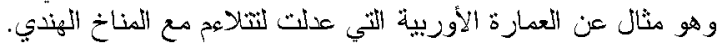




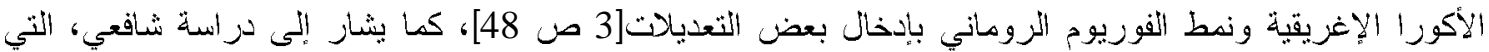

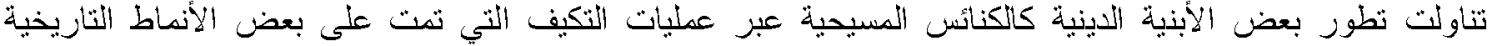

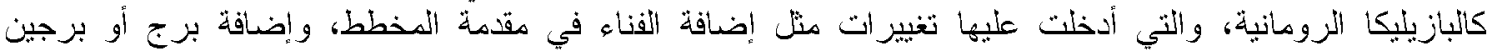

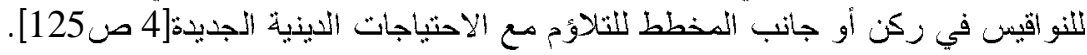

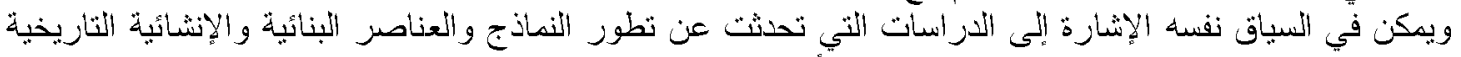

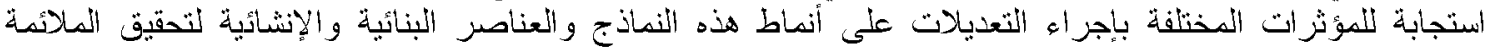

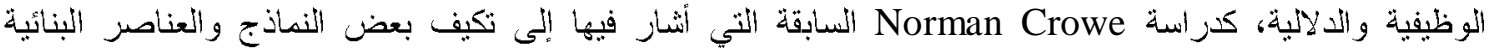

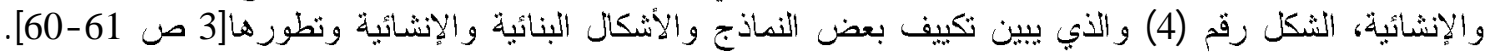

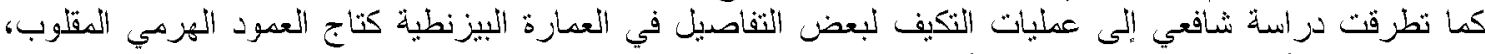

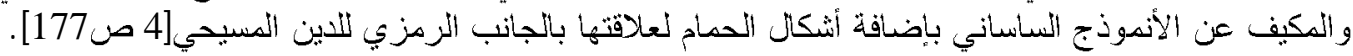

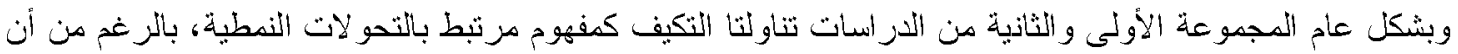

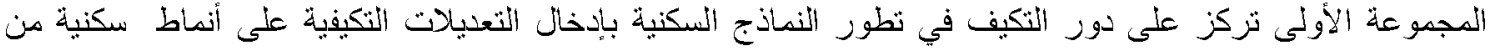

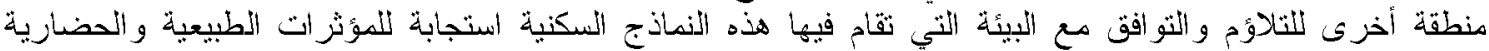

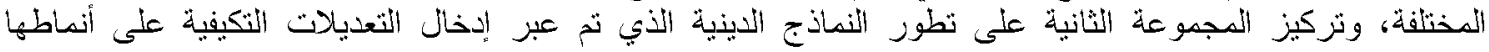

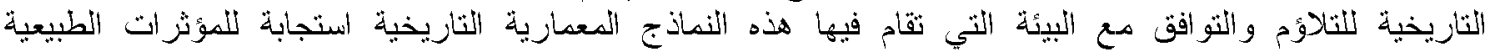

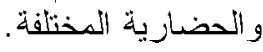

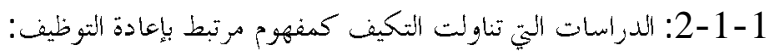

وتضم النراسات التي تناولت إنخال التعديلات على مستوى الأبنية المنفنة (بمعنى إعادة التوظيف) كاستجابة اللتغير

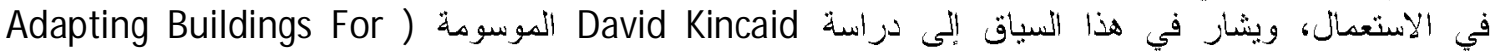

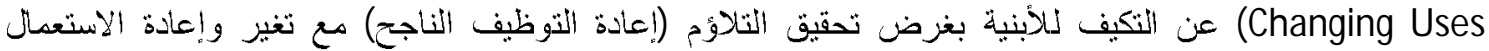

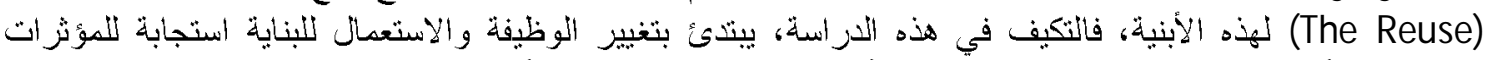

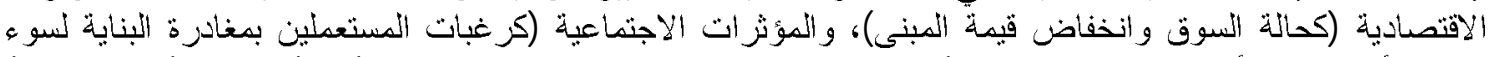

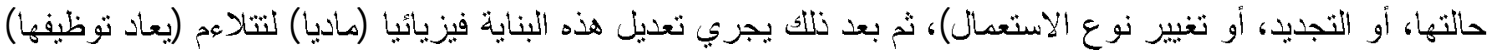

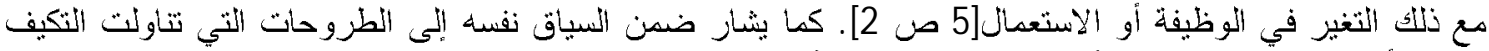

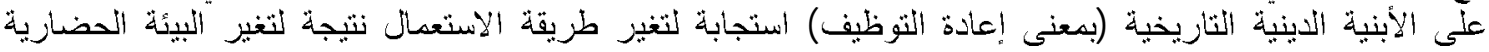

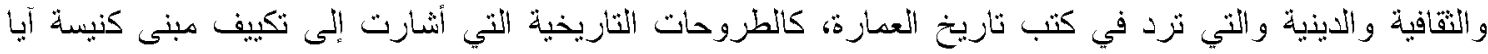

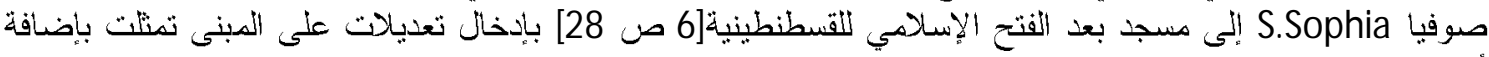

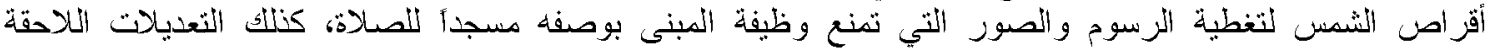

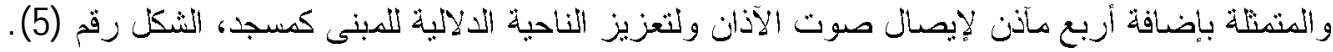

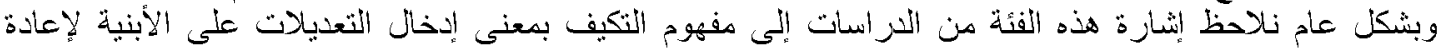

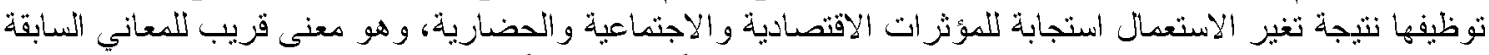

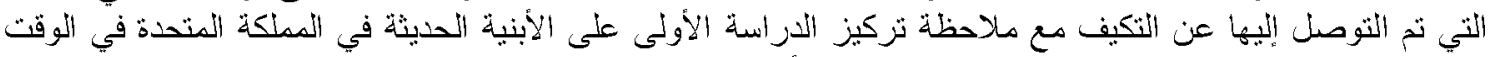
الزر أهن بحكم موضو ع التدر انسة، و الدر اسة الثنانية على الأبنية التاريخية.

2-2 2- الدراسات اني تاولت التكيف كمفهوم مرتبط بالتحو لات الشكلية ضمن العملية التصميمية:

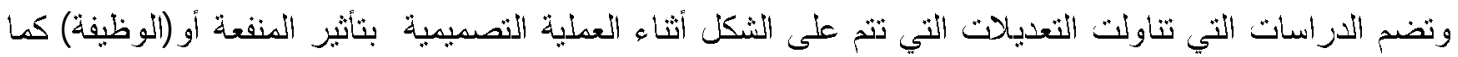

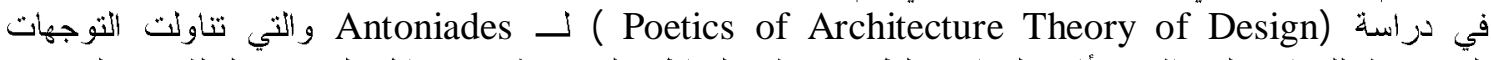

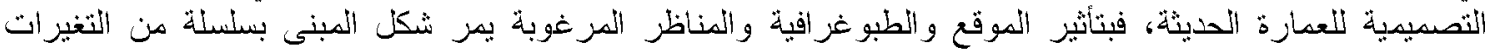

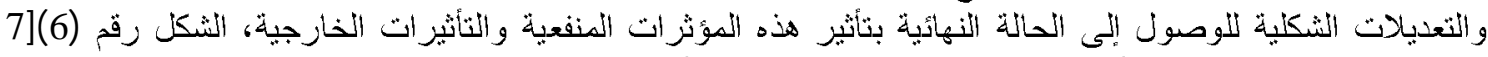

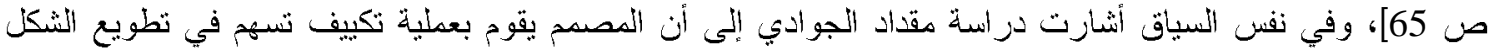

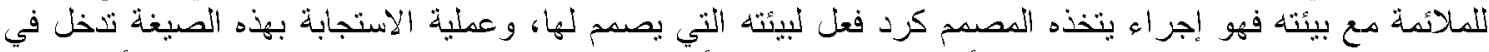
صلب العمنية التصميمية، فهي تزكيب أجزاء الشكل وفقا لتأثير التوى الخارجية، فالثكل هو رد فعل لتأثير البيئة المحيط:[8 صن 66] وفي العملية التصميمية لتوجهات عمازة ما بعت الحداثة بدأ النشكل و التصميم ينأثزان بمؤثرات أخرى نبذت من 


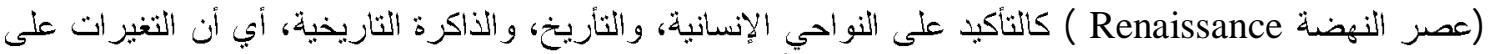

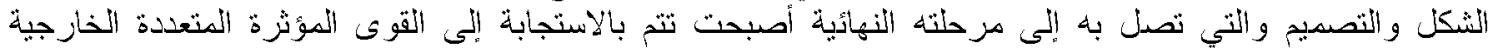

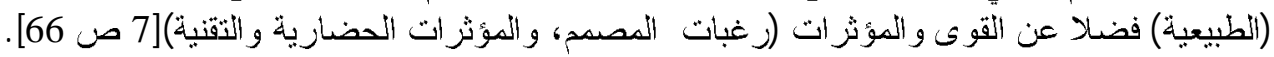

$$
\text { 3-2 الدراسات التي تناولت التكيف كمفهوم مرتبط بسهونة التحوير والمرونة: }
$$

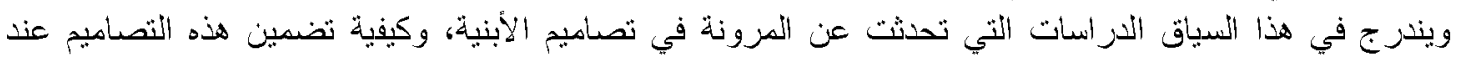

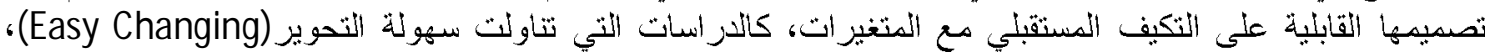

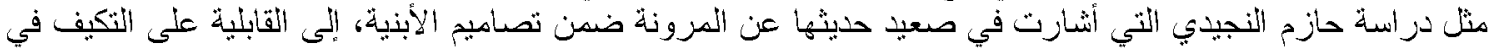

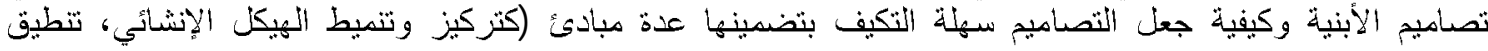

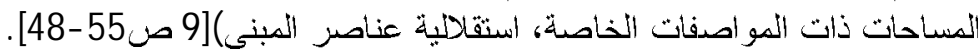

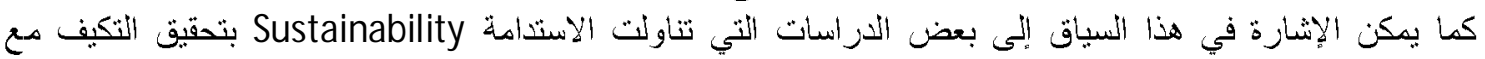

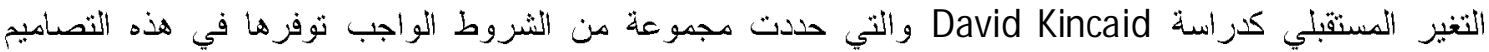

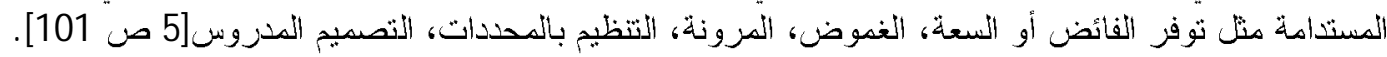

وفي النهاية بلاحظ تنوع واختلاف الجوانب و المفاهيم التي ارتبط بها مفهوم التكيف ضمن الثراسات المعمارية

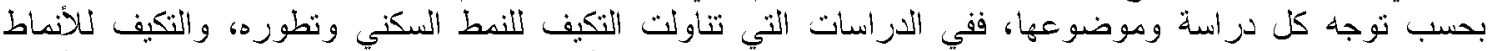

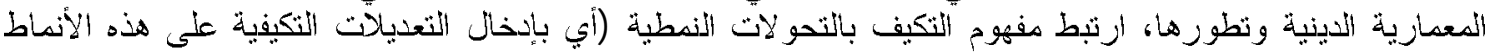

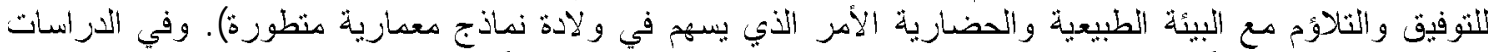

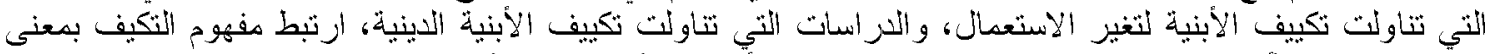

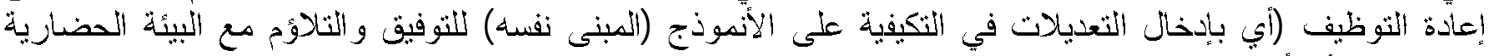

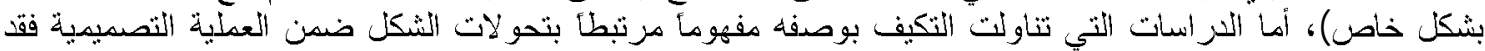

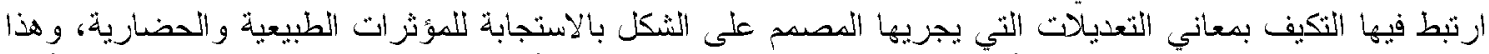

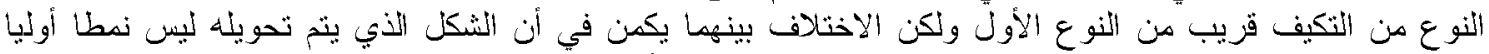

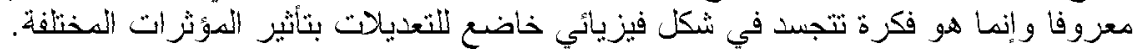

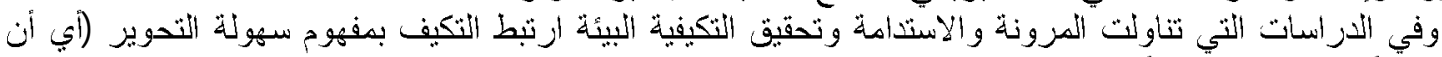

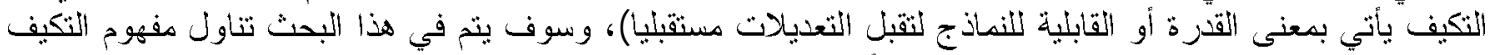

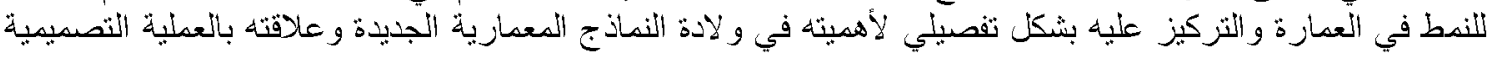

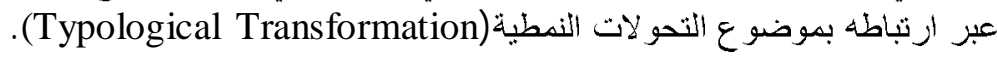

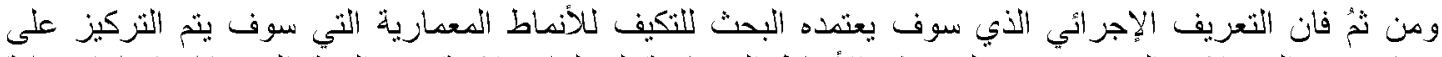

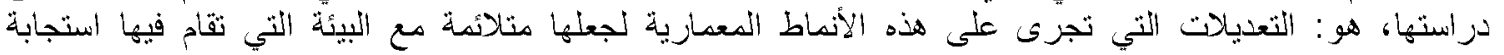

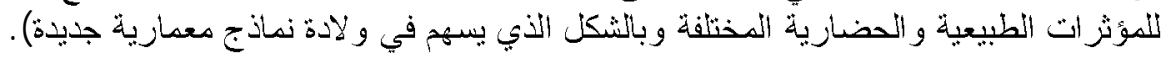

$$
3 \text { - مفهو م النمط وتكيفه في العمارة: }
$$

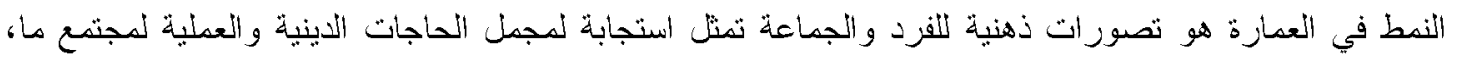

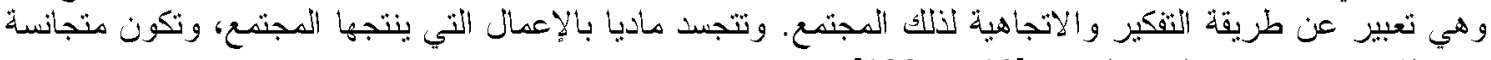

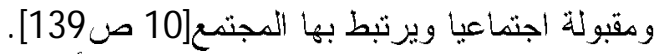

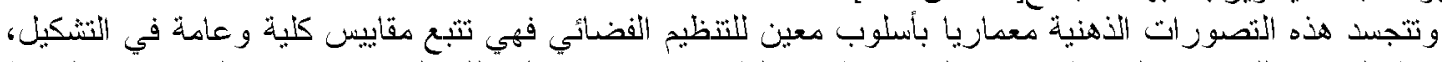

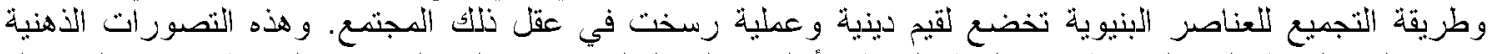

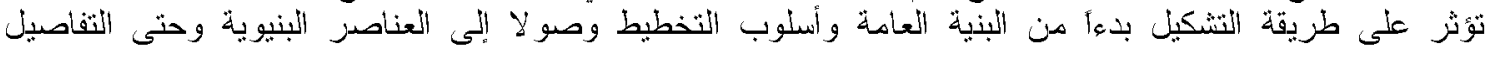

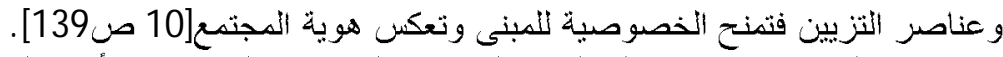

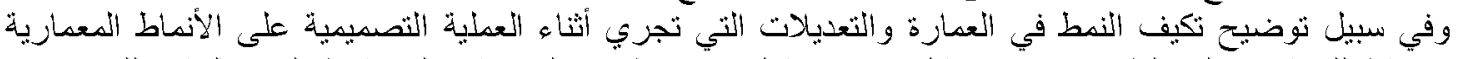

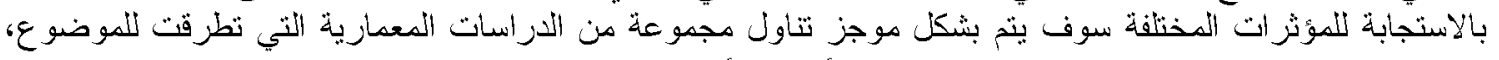

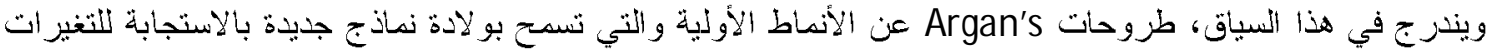

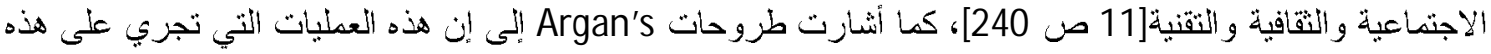




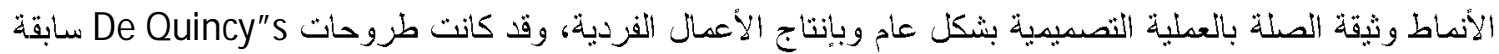

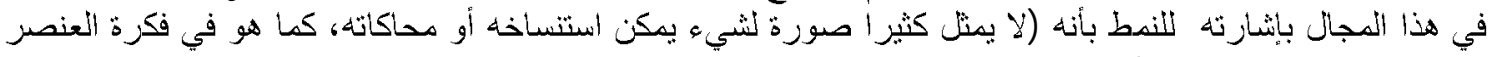

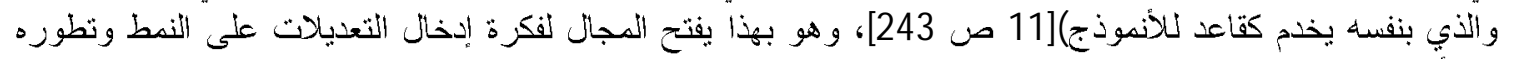

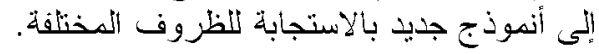

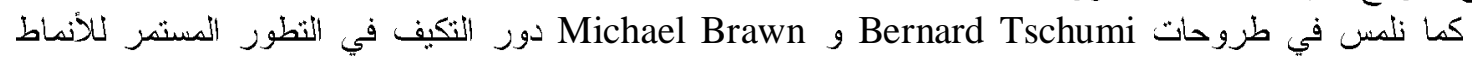

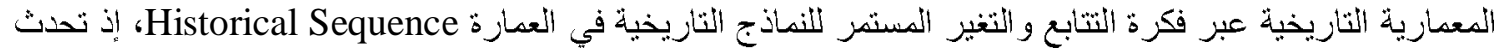

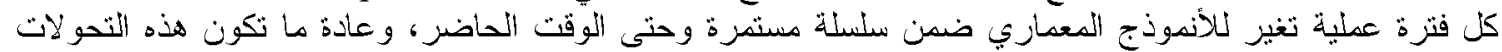

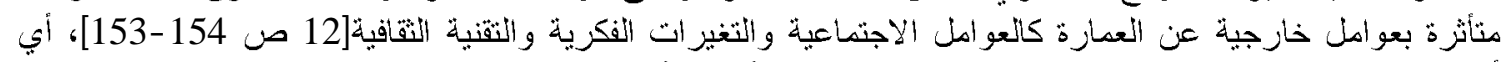

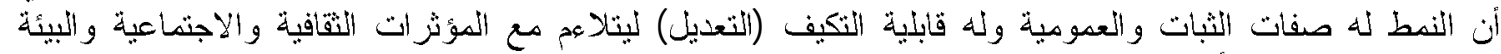

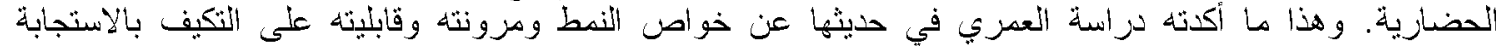

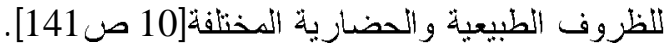

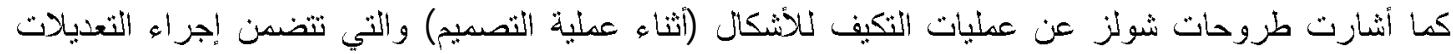

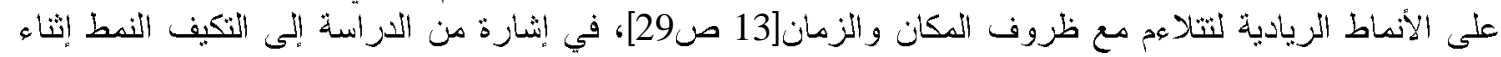
عطية التصميم المعماري. ونلمن في طروحات التهات الإشارة إنى تكيف النمط في تأكيده على أهمدة الأنماط الزيادية في العملية

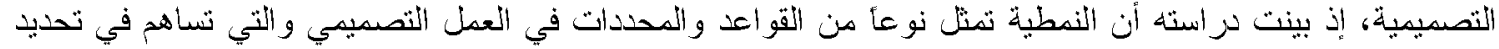

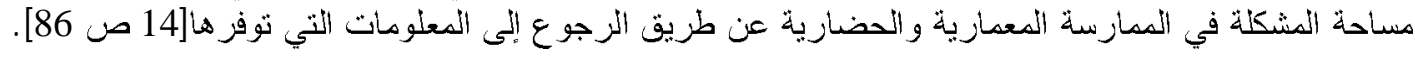

نستتج مما سبق أن النمط هو تصورات ذهنية للفرد والجماعة تمثل استجابة لمجمل الحاجات التينية و العطلية

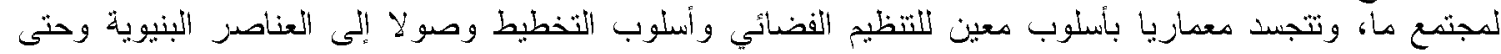

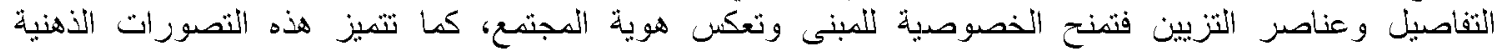

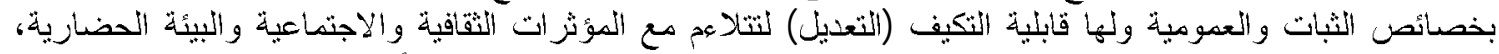

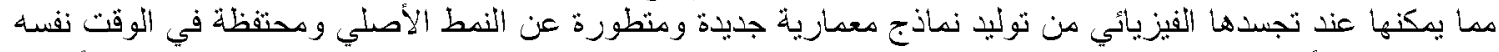

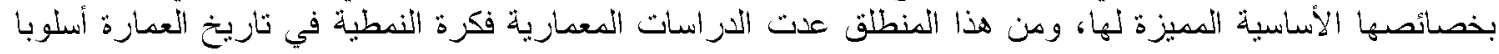

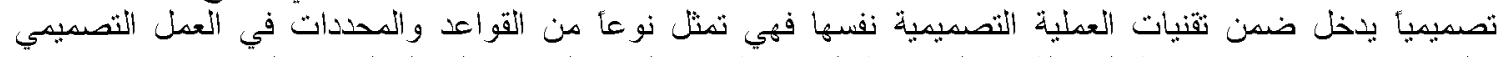

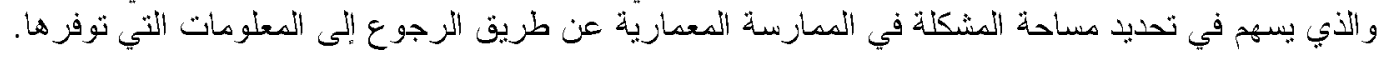

$$
4 \text { - التكيف وموضوع التحولات: }
$$

من أجل تتاول تكيف الأنماط المعمازية والأي يتم بإجزاء (تعنيلات) على الأنماط الأوذية (Prototype) و الممثلة

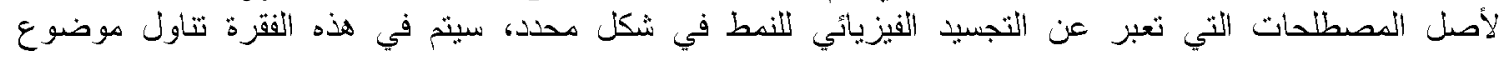

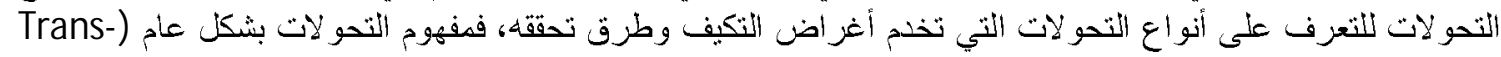

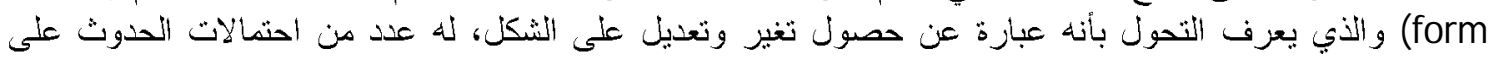

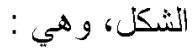

تغير في الثنكل و المظهز تغيز في الطبيعة و الخغل ولنية

في إشارة إلى إن جو انب إحداث التغيز بمكن أن تكون منعلقة بالمظهر و الهيئة أو بالجوهر والمضمون15 ص

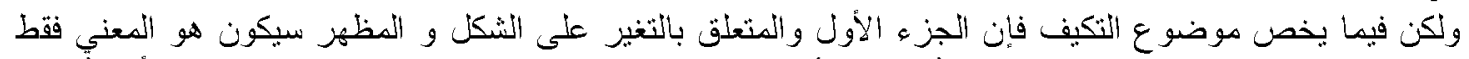

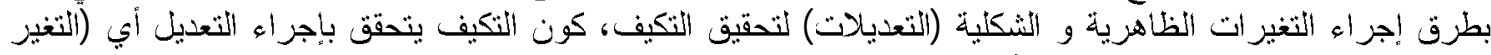

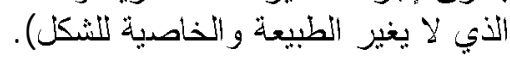

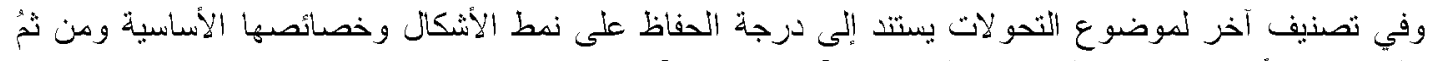

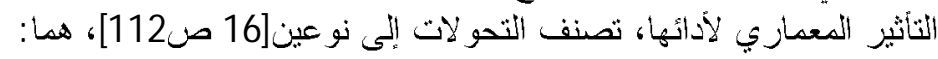

1-4 التحو لات المحافظة أو المقفلة:

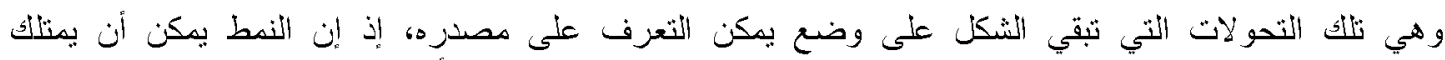

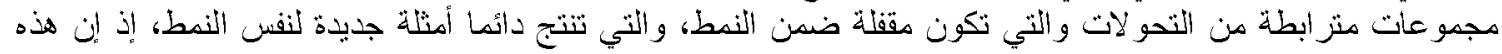




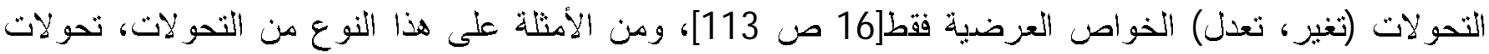

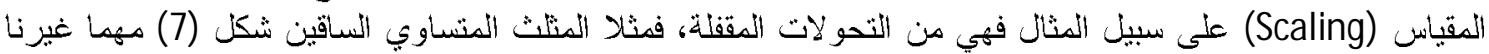

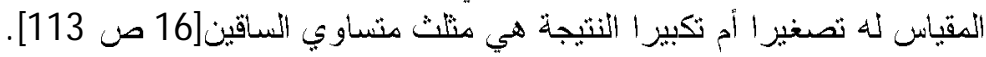

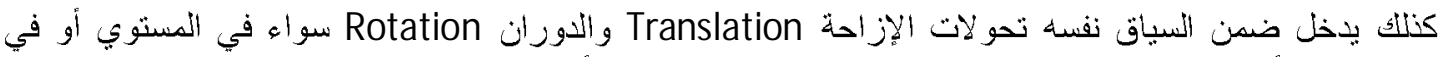

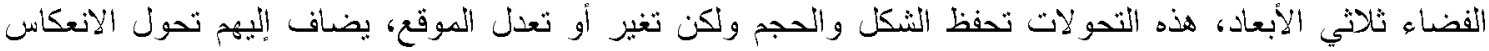
Reflection

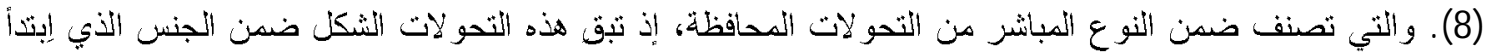

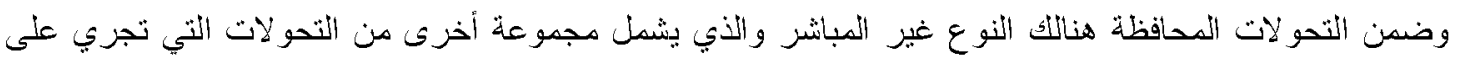

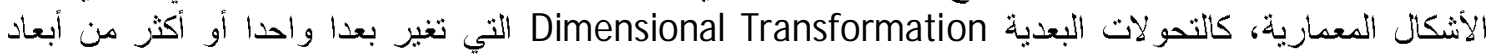

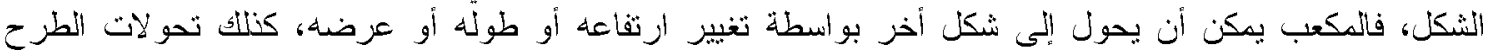
Subtractive Transformation

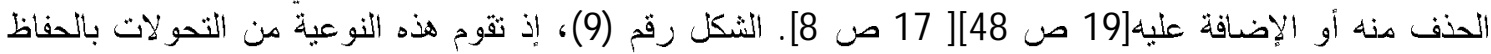
على الخواص الأساسية للنكل بذون تغييز، بينما تنغير الخصائص العرضية المتنوعة.

4 -2: التحو لات النهذامة أو غيز المقفلة:

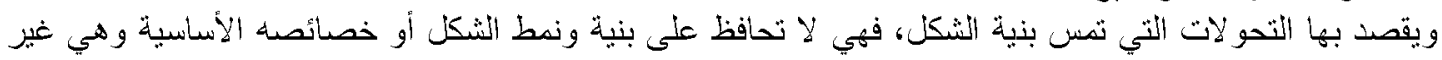

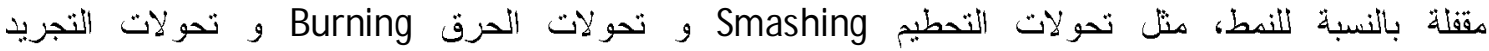
Dismantling

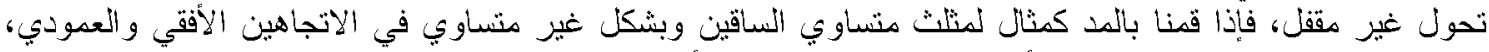

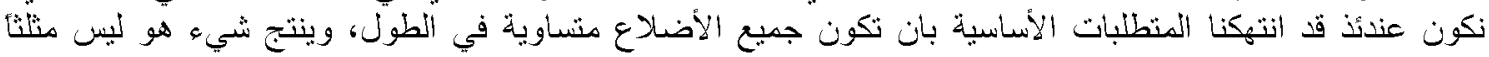

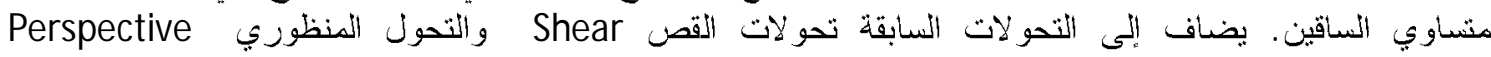

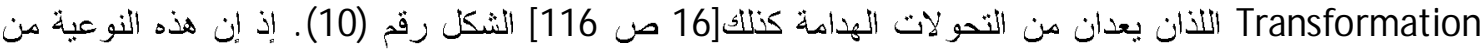

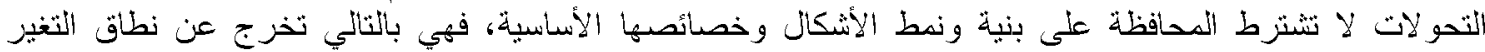
المحدو (النعديل) الأي يقوم عليه فنهوم التكيف.

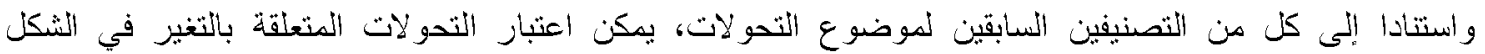

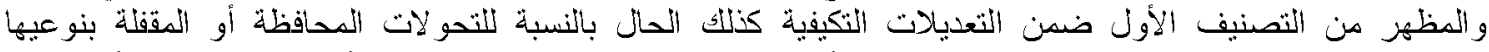

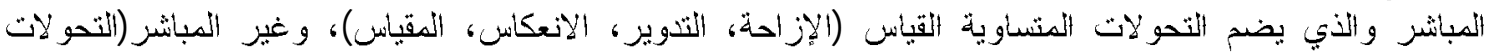

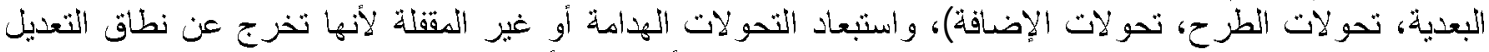

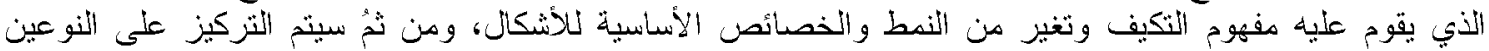

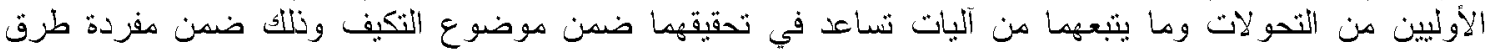
و آليات النكيف في الإطار النظري الذبي سوف ينت وضتهها في الفقرة القادهة.

5 - الإطار النظرب التفصيلي لتكيف الأنماط في العمارة:

تم فيما سبق توضيح التعريف الإجزاثي للتكيف للأنماط المعمارية، حيث وضح التعزيف بأن الأنكيف نهذه الأنماط:

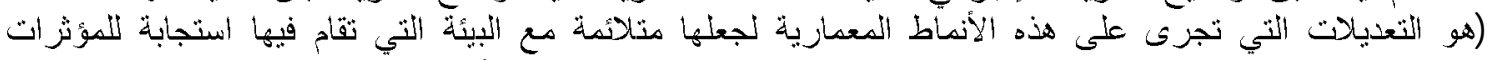

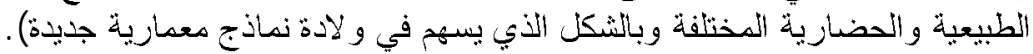

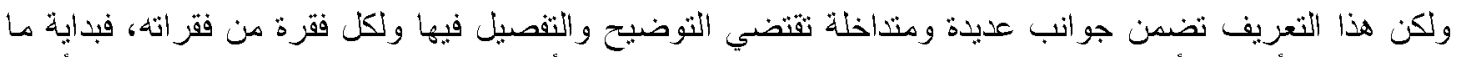

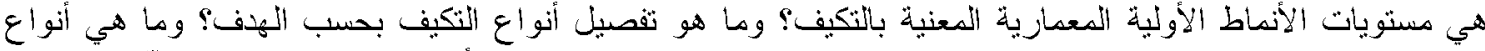

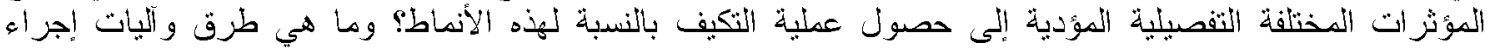

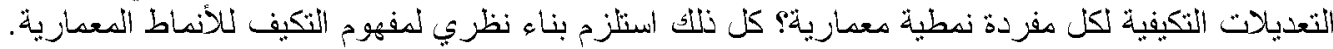
مفردات الإطن النظري: 


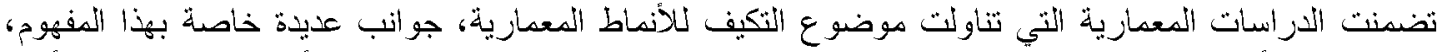

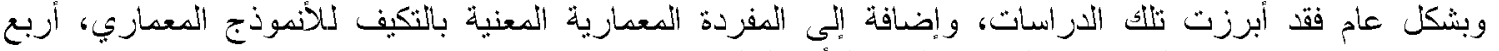
مفردات رئيسة يتركز حولها مفهوم النتكيف بالنسبة نلأنماط المعمارية ، وهي:

$$
\begin{aligned}
& \text { 5-1 } 5 \text { - مستويات حصون التكيف: }
\end{aligned}
$$

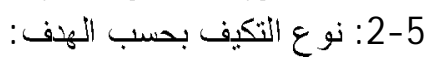

$$
\begin{aligned}
& 5 \text {-3: } 5 \text { - نوع المؤثر المسبب للتكيف: } \\
& 5 \text {-4: طرق و وانيات تحقيق التكيف: }
\end{aligned}
$$

1- 5

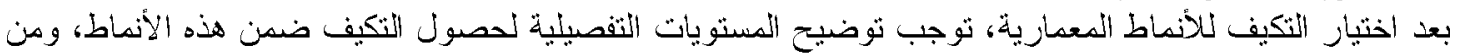

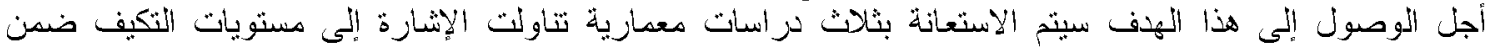

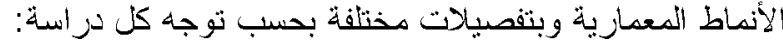

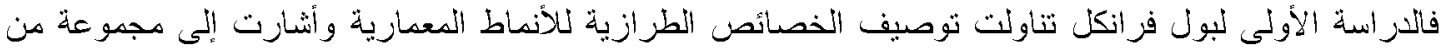

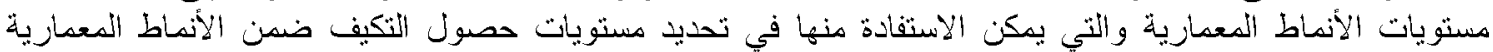

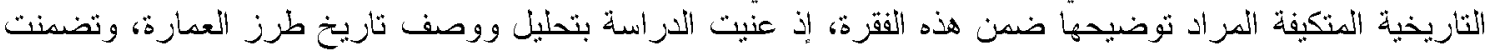

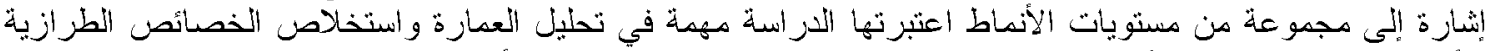

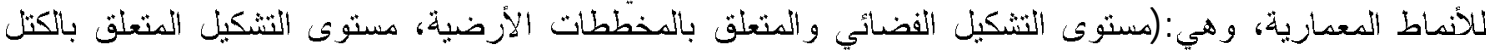

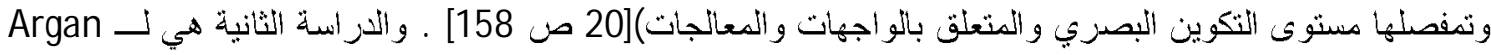

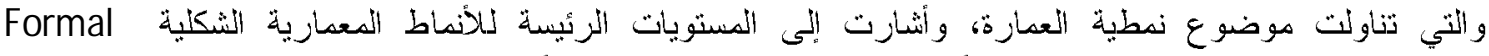

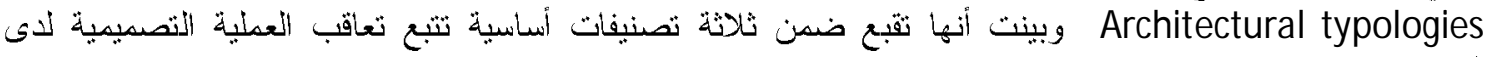

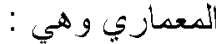

الأنماط المرتبطة بالتشكل الكلي للمبنى Complete Configuration of building؛ (مستو المخطط). الأنماط المرتبطة بالعناصن الهيكلية الرئيسة Major structural elements، كأنماط التسقيف، وأنظمة الإنشاء

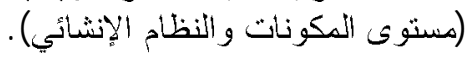

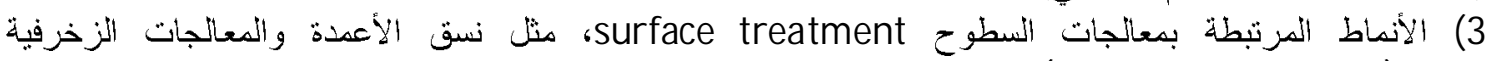
و غيره.(مستوى المعالجات التزيينية). أبي أن هنالك أنماطا للمخطط الأفقي Plan و أخزى لنظم الإنثاء و المكونات Structural system و الثنة لمعالجات

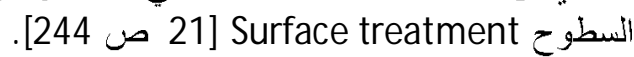

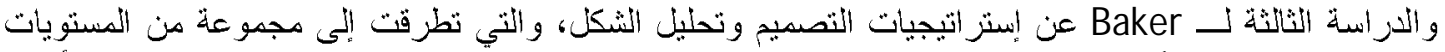

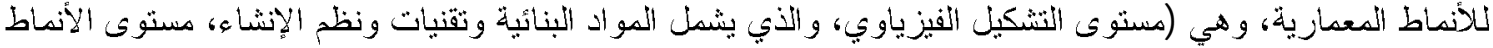

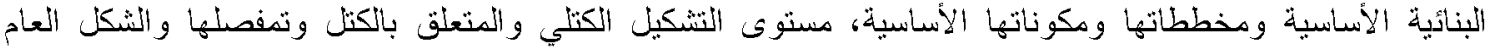

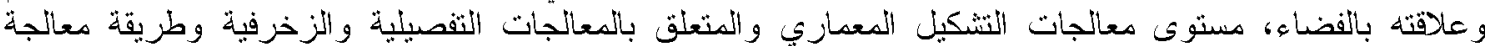

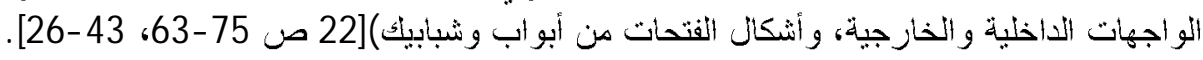

وبعد الاطلاع على المستو يات التي أندارت إنيها اللدراسات الثلاث السابقة تم اعتماد أربعة مستويات أساسية

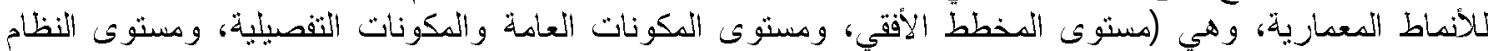

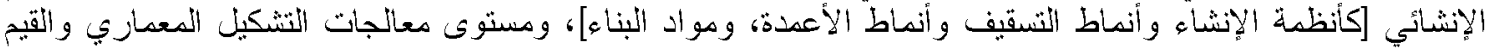

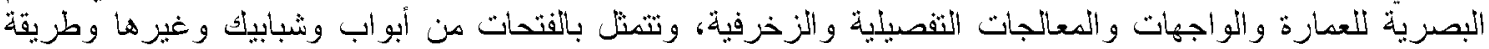

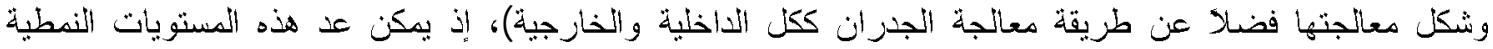

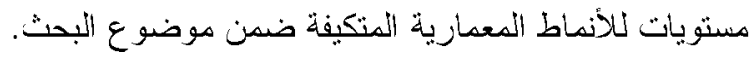

$$
5 \text {-2: }
$$

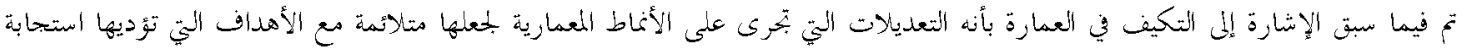

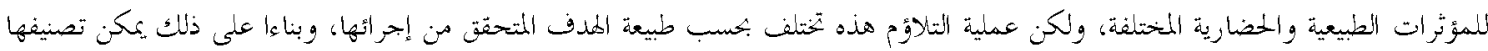
إلى ثلاث بجاميع، وكما يأتي: 


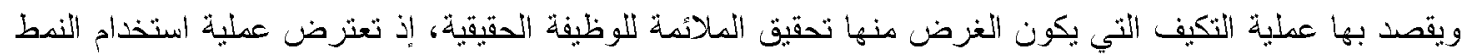

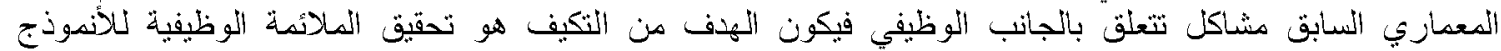

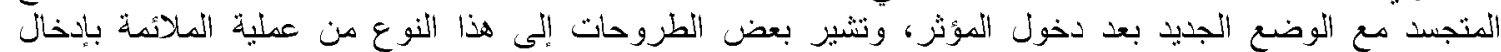

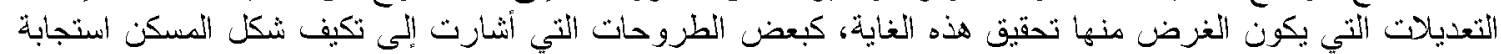

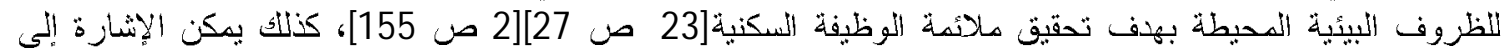

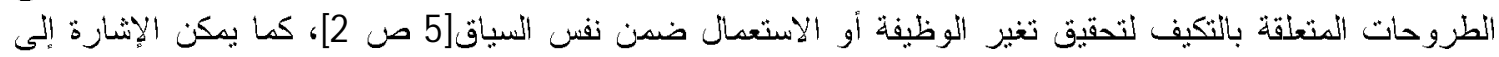

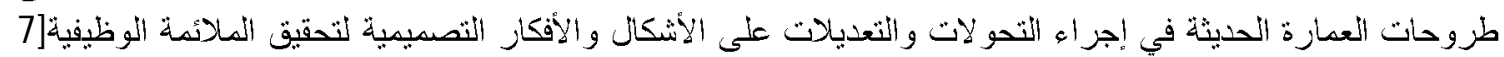

ص

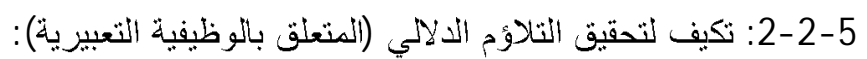

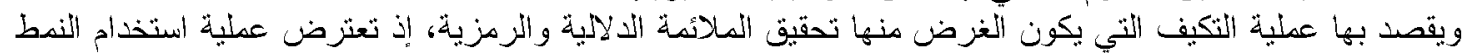

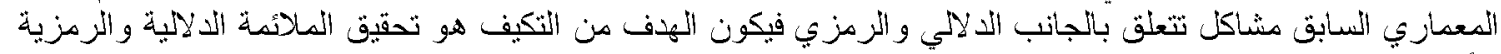

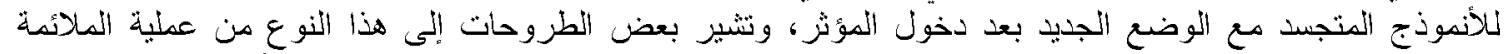

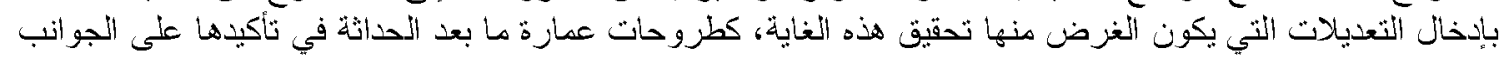

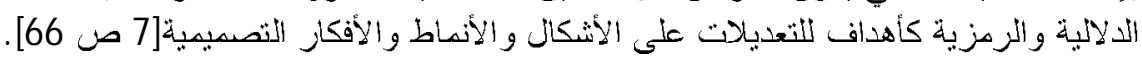

$$
5 \text {-2 -3: تكيف لتحقيق التنلاؤم التوظيفي والتلالي: }
$$

ويقصد بها عملية التكيف التي يكون الغزض كنها تحقيث الملائمة للوظيفة الحقبقية، فضلا عن تحقيق الملائمة

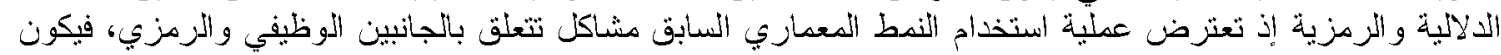

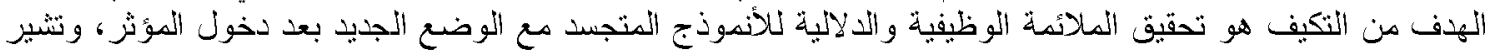

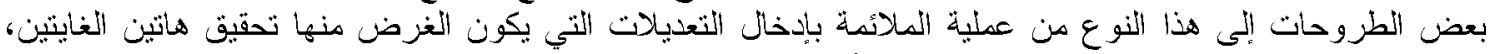

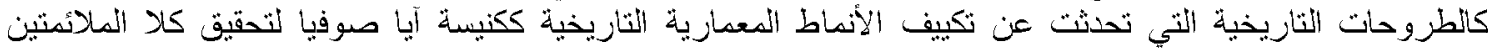

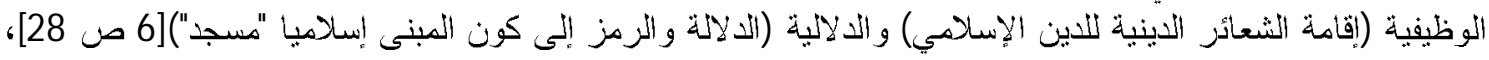

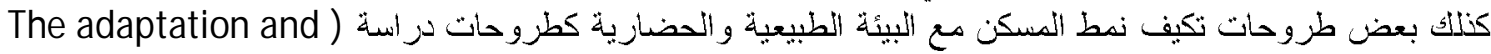
(Bungalow) السكني لتحقيق الملائمة الوظيفية و الثلالية

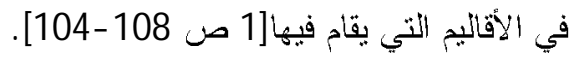

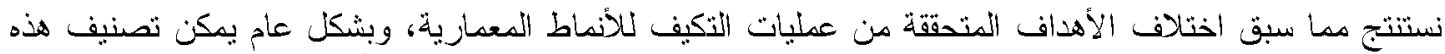

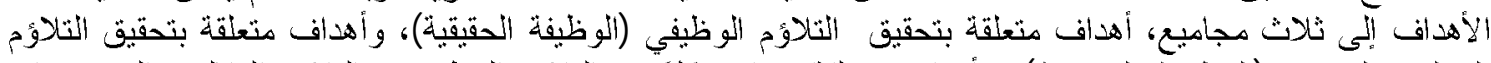

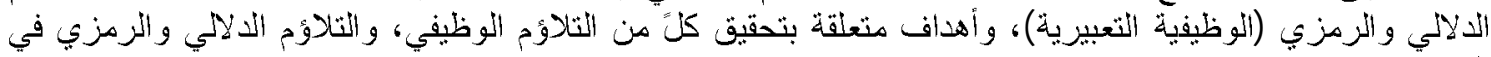

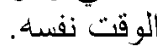

$$
5 \text {-3: نوع المؤثر المسبب للتكيف: }
$$

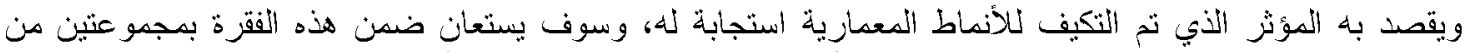

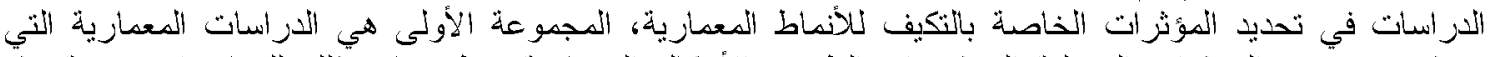

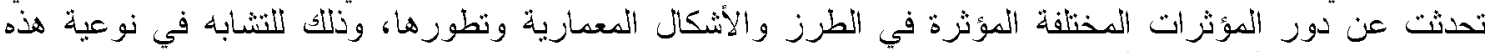

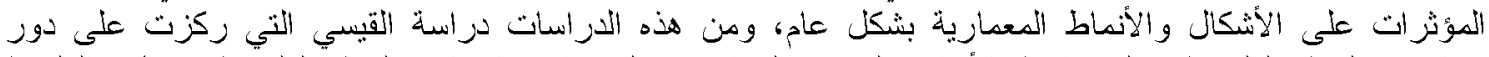

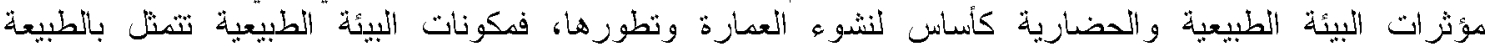

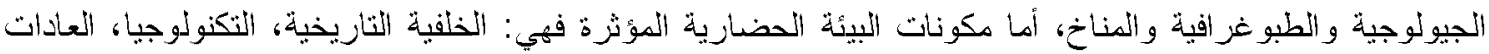

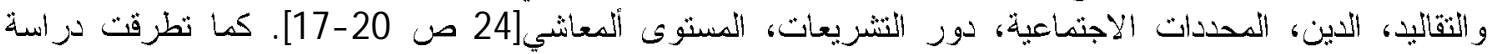

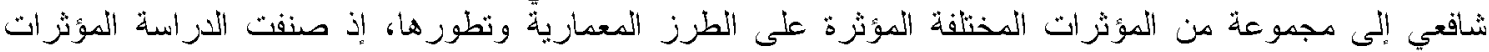

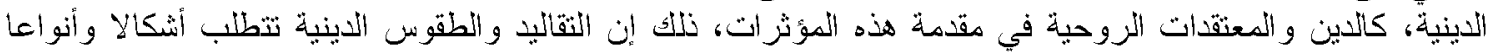

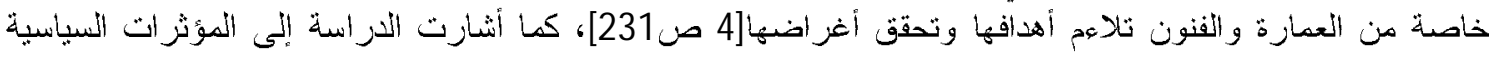




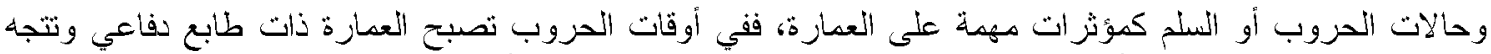

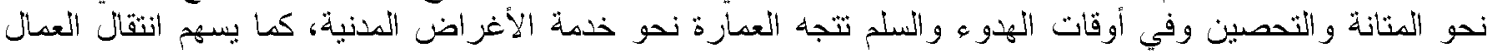

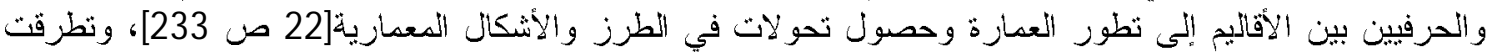

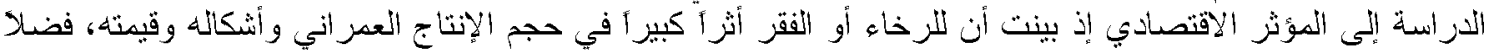

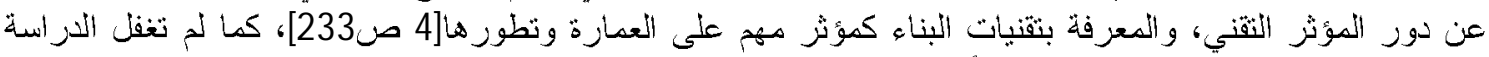

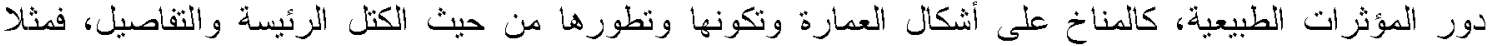

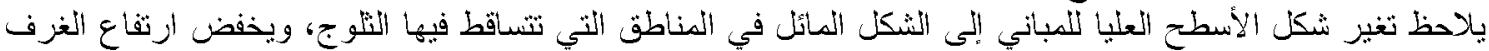

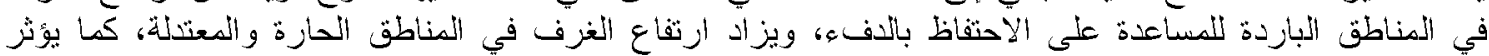

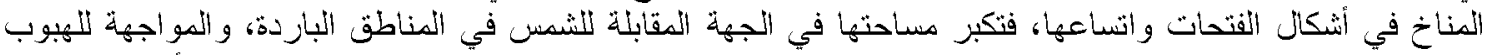

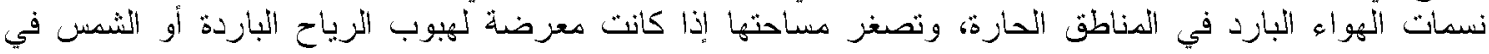

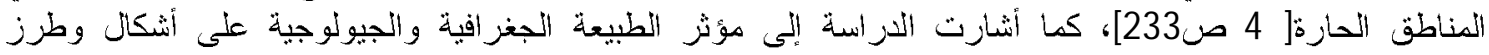

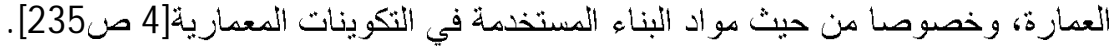

أما المجموعة الثثانية من اللراستات وانتي يمكن الاستفادة منها في تحديخ المؤثرات المسببة للتكيف نلانماط

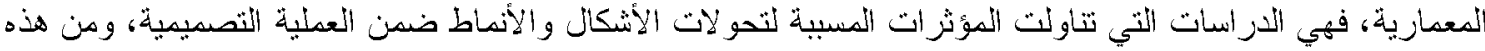

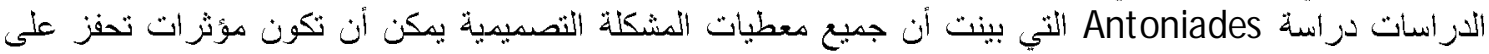

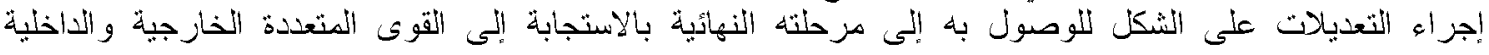

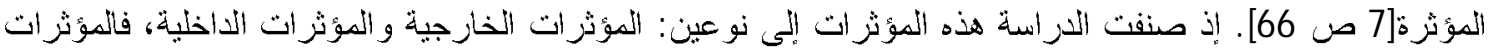

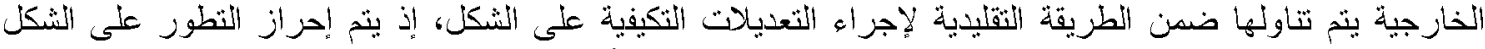

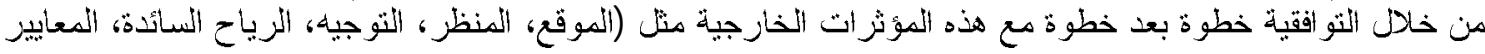

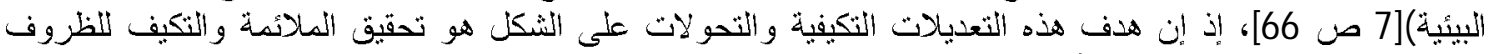

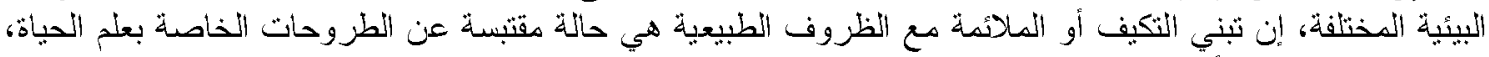

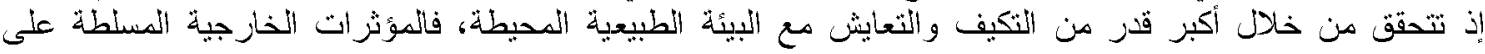

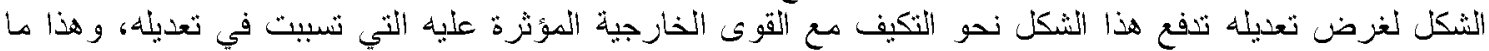

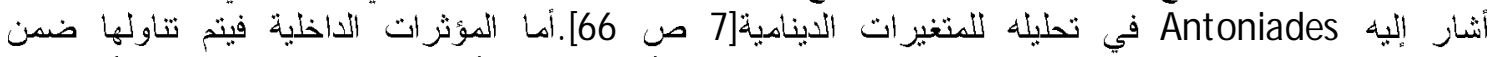

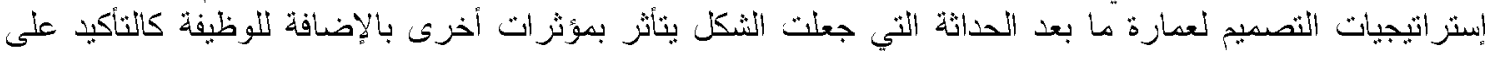

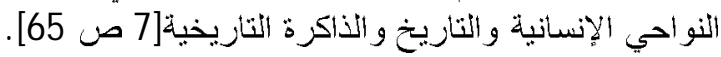

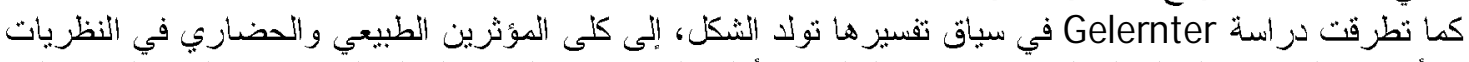

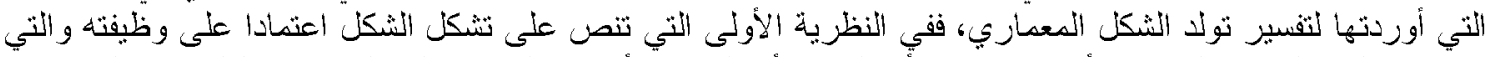

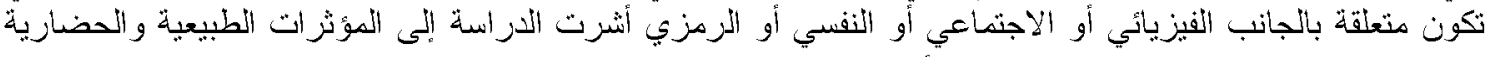

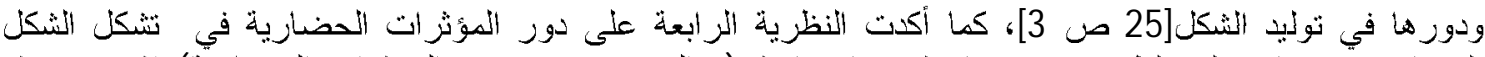

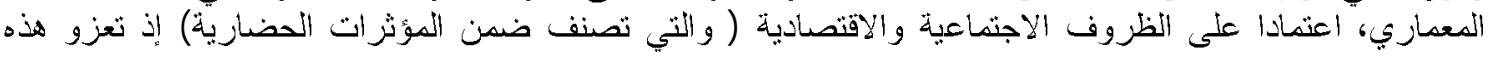

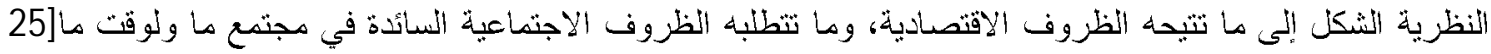

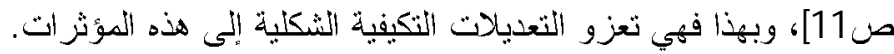

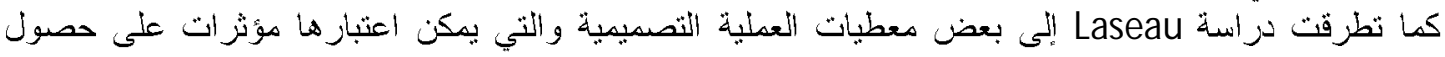

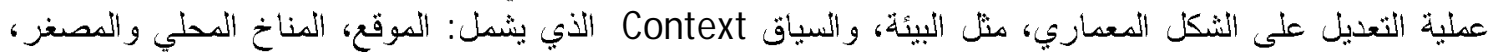

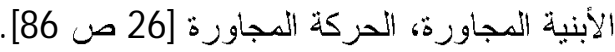

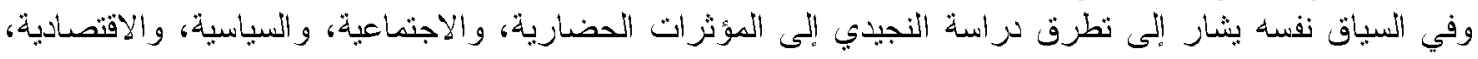

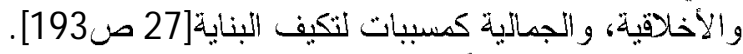

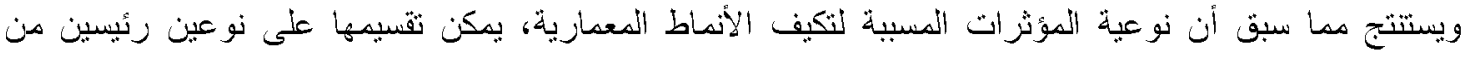

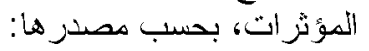

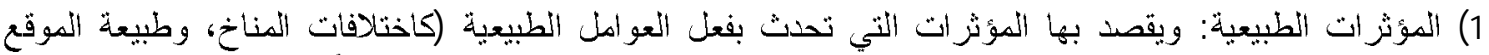

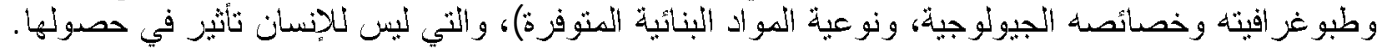

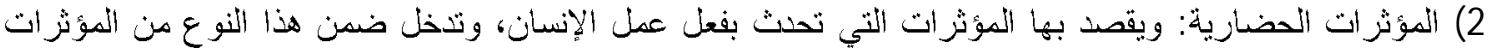

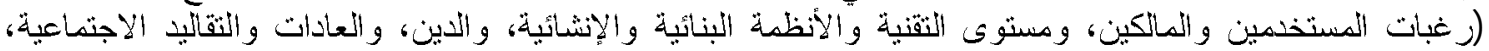

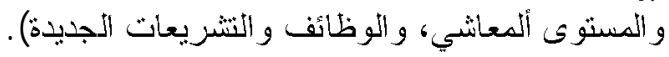




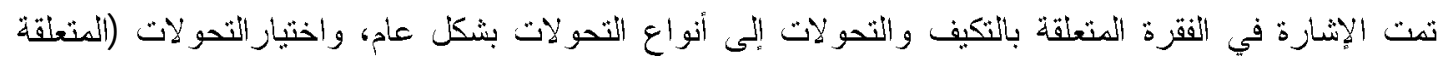

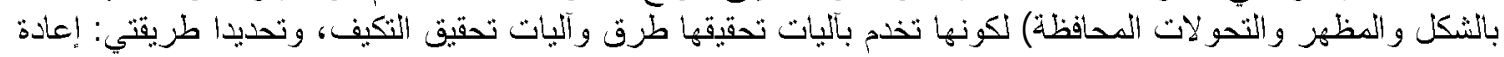

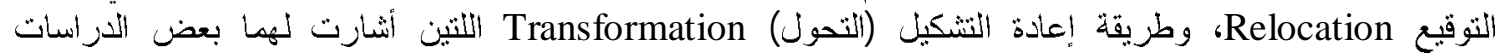

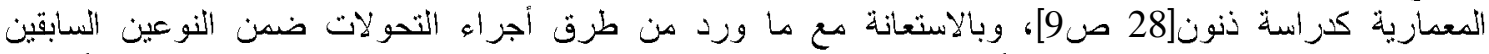

للتحو لات التي تدت الإنشارة إليهما في أعلاه، يمكن تعداد مجموعة من الآليات التفصيلية ضمن كل طريقة وكما يأتي:

$$
\text { 1-4-5 }
$$

و تتح هذه الطريقة لتحقيق التكيف باستخدام مجمو عة من أليات التحون التي تتضمن عدم حصول الإضاففة أو الطزح

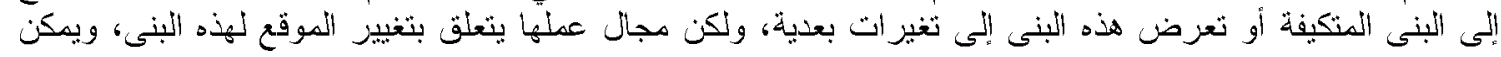

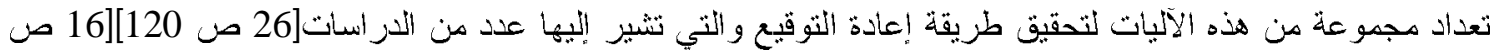

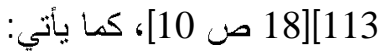

$$
\begin{aligned}
& \text { الالانعكاس والتقلب التباس } \\
& 6 \text {-4 -2: طزيقة إعادة النشكيل ( التحول ضمن الثكل الظاهري): }
\end{aligned}
$$

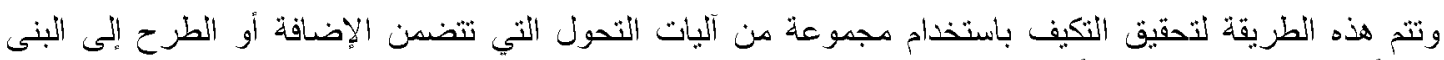

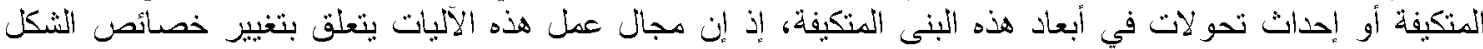

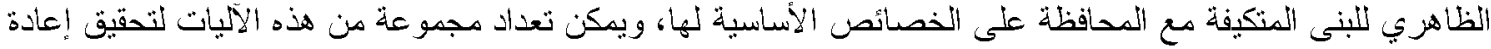

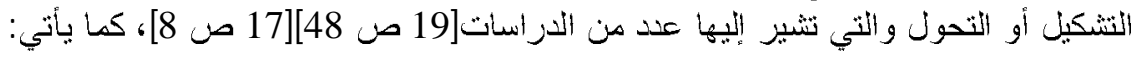

$$
\begin{aligned}
& \text { التحو لات البعدية Dimensional Transformation آليات إجراء التحو لات ضمن النشكل }
\end{aligned}
$$

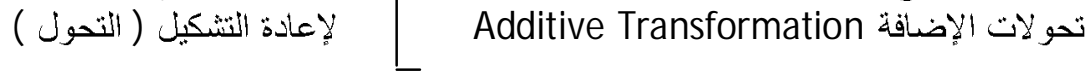

إنستنج مما سبق وجود طزيقتن أساسيتين لتحقيق التكيف للأنماط المعمارية، هما طريقة إعادة التوقيع، وطريقة

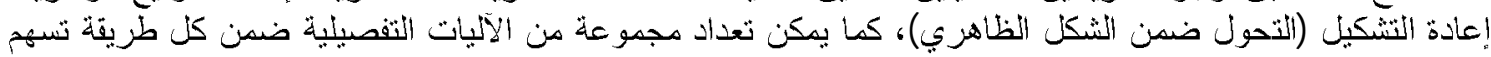

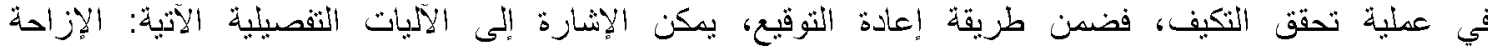
Translation

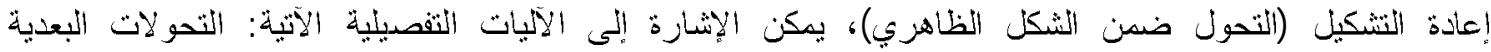
Dimensional Transformation .Additive Transformation

$$
7 \text { - الخلاصة و استتناجات البحث: }
$$

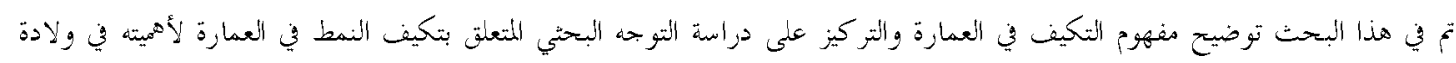




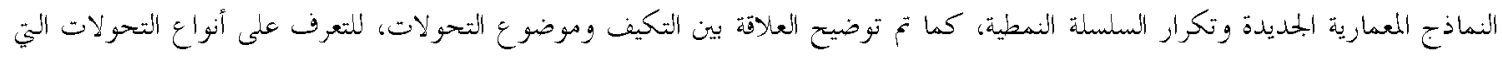

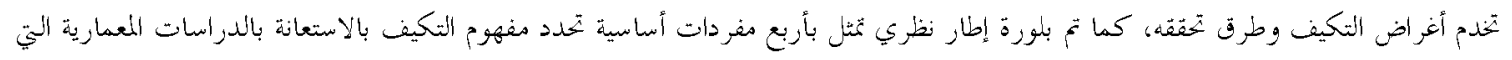

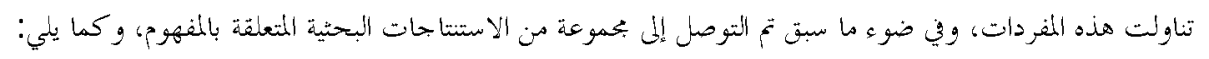

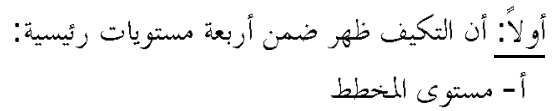

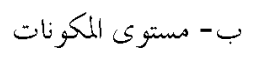

$$
\begin{aligned}
& \text { ج - مستوى النظام الإنشائي و المواد البنائية } \\
& \text { د- مستوى الواجهات والثزينين }
\end{aligned}
$$

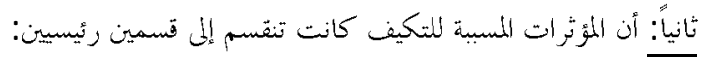

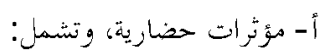

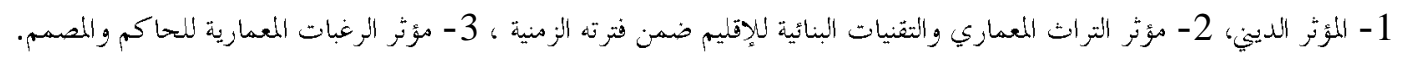

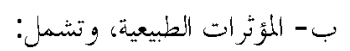

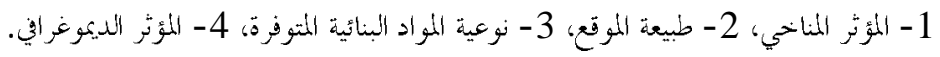

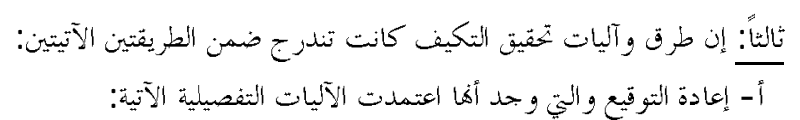

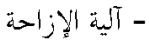

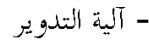$$
\text { - آلية الإنعكاس النداس }
$$$$
\text { - آلية المقياس - }
$$$$
\text { - آنية تغيير المادة }
$$$$
\text { ب - إعادة التشكيل والتي و وحد أها اعتمدنت الآليات التفصيلية الآتية: }
$$$$
\text { - آلية الإخافة - }
$$$$
\text { - آلية الطرح ح - البة }
$$$$
\text { - آلية التحولات البعدية }
$$

$$
\begin{aligned}
& \text { رابعاً: إن الأهداف المتحقُقة من عمليات التكيف كانت تندرج خمن الأهداف الآتية: } \\
& \text { - الأهداف الوظيغية } \\
& \text { - الأهداف الدلالية } \\
& \text { - الأهداف المشتر كة الوظيفية الدلالية }
\end{aligned}
$$

$$
\text { مصادر البحث: }
$$

1.Desai, Miki, Madhavi Desai, " The Adaptation and Growth of the Bungalow in India“, Article has been published at the International Workshop on the Architectural Heritage of Asia and Oceania (UIA Workgroup on Heritage) at the Rizvi College of Architecture, Bombay, in December 1995.

2.Abel, Chris," Architecture and Identity Towards a global eco-culture", First Ed, Architectural Press, London, 1997. 
3.Crowe, Norman," Nature and The Idea of A Man - Made World", First Ed, Massachusetts Institute of Technology, 1997.

4. شافعي، فريد، " العمارة العربية في مصر الإسلامية عصر الو لاة "، المجلد الأون، الهيئة المصرية العامة للتأليف

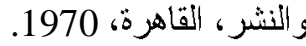

5.Kincaid, David, "Adapting Buildings For Changing Uses Guidelines for Change of Use Refurbishment", First Ed, Spon Press, London, 2002.

6.عبد الجواد، توفيق أحمد، " تاريخ العمارة العصور المتوسطة الأوربية والإسلامية"، ط2، مكتبة ألانجلو المصرية،

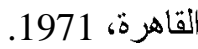

7. Antoniades, C. Anthony, “Poetics of Architecture Theory of Design”, John Wiley \& Sons ,Inc , New York, 1992.

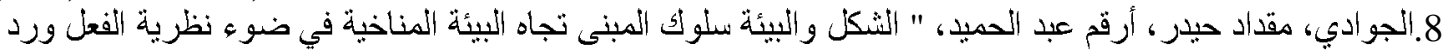

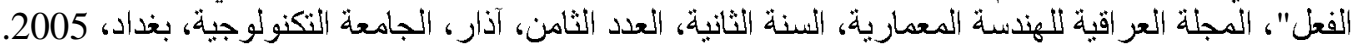

9.Nijaidi, H.R, "Flexibility In The Design of Buildings ", thesis, Oxford Polytechnic, In Collaboration with Bartlett School of Architectural \& Planning Univ. Collage, London ,Oxford, 1982, P 106.

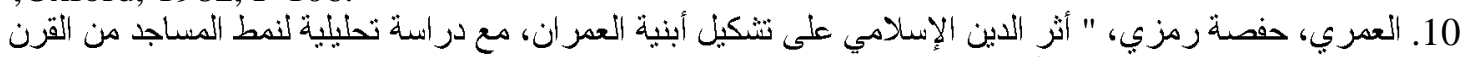

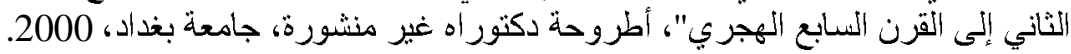

11.Nesbitt, Kate, "Theorizing a New Agenda For Architecture ", Princeton Architectural Press, New York, 1996.

12.Tschumi,Bernard, “Architecture \& Disjunction “, MIT Press, Cambridge, London, 1994.

13.Schulz, Christian Norberg, " The Concept of Dwelling “, Rizzoli International Publications, New York, 1985.

14. Row, Peter, "Design Thinking”, MIT Press, Cambridge, London, 1988.

15.A.S.Hornby, "Oxford Advanced Learner's Dictionary of Current English", Oxford University Press, 3Ed, London, 1974.

16.Mitchell, William J., " The Logic Of Architecture, Design, Computation, and Cognition “, $3^{\text {rd }}$ Ed, The MIT Press, London, 1992.

171.Chase, S. C., “ Modeling Designs With Shape Algebra's and Formal Logic “, Ph.D. dissertation, University of California, Los Angeles, 1996.

18.Gero, J. S., " Shape pattern recognition using a computable shape pattern representation ", Artificial Intelligence in Design, Kluwer, Dordrecht, 1998.

19.Ching, Francis, D.K., “ Architecture, Form, Space, and Order”, $2^{\text {nd }}$ Ed, John Wiley \& Sons, inc, U.S.A, 1996.

20.Frankl, Paul," Principles Architectural History -The Four Phases of Architecture Style: 1420-1900”, 1968.

21.Argan, Guilio Carlo, “ On Typology of Architecture “, Architectural Design, Vol 33, No.11/12, London, 1963.

22.Baker, Geoffrey H., " Design strategies in Architecture- an approach to the analysis of form”, $2^{\text {nd }}$ ED, St. Edmundsbury Press Ltd, Great Britain, 1996.

23.Broadbent, Geofrey ,"Design in Architecture, Architecture and the Human Sciences", David Fulton Publishers, London, 1988.

24.Kaissi, S., " The Role of Nature \& Cultural Environment 0n the fabric of the city", Vol. 1, Ph.D. Thesis, University of Sheffield, 1983.

25.Gelernter, Mark, " Sources of Architectural Form”, Manchester University Press, Manchester \& new York, 1995.

26.Laseau, Paul," Graphic Thinking for Architects \& Designers", $3^{\text {rd }}$ Ed, John Wiley \& Sons, Inc, New York, 2001. 27.النجيدي، حاز مر اشد، " منهجية التصميم المعماري"، الجامعة التكنولوجية، قنم الهندسة المعمارية، بغداد، 1992. 
28. ذنون، أحمد عبد التواحد، " دور التكيف في تطور عمارة المساجد"، أطروحة دكتور اه غبر منشورة، الجامعة

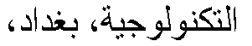

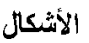
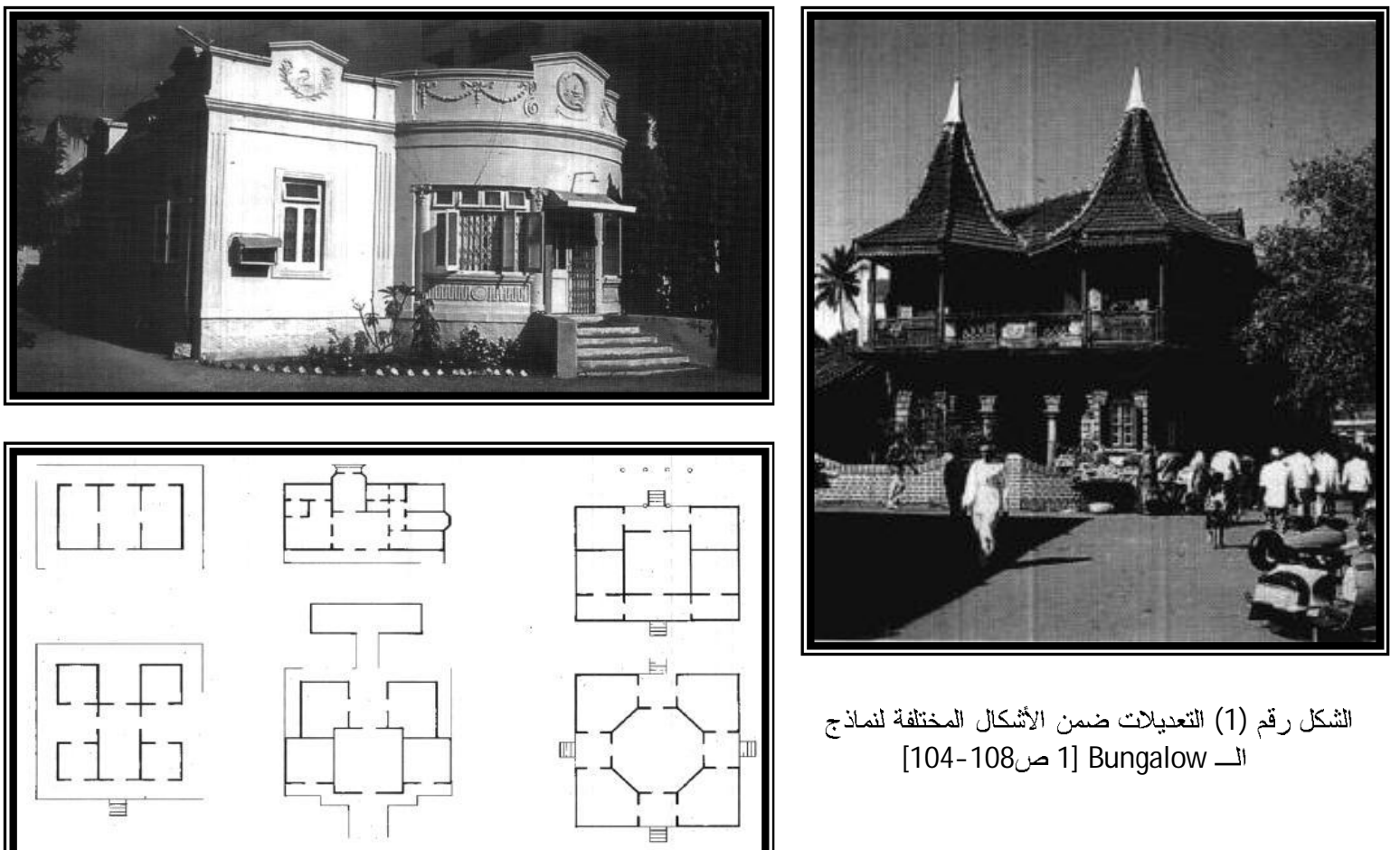

الثنكل رقم (1) التعديلات ضمن الأثكال المختلفة لنماذج

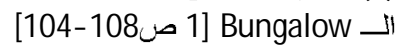

ABSTRACTED PLAN TYPES OF THE BUNGALOW
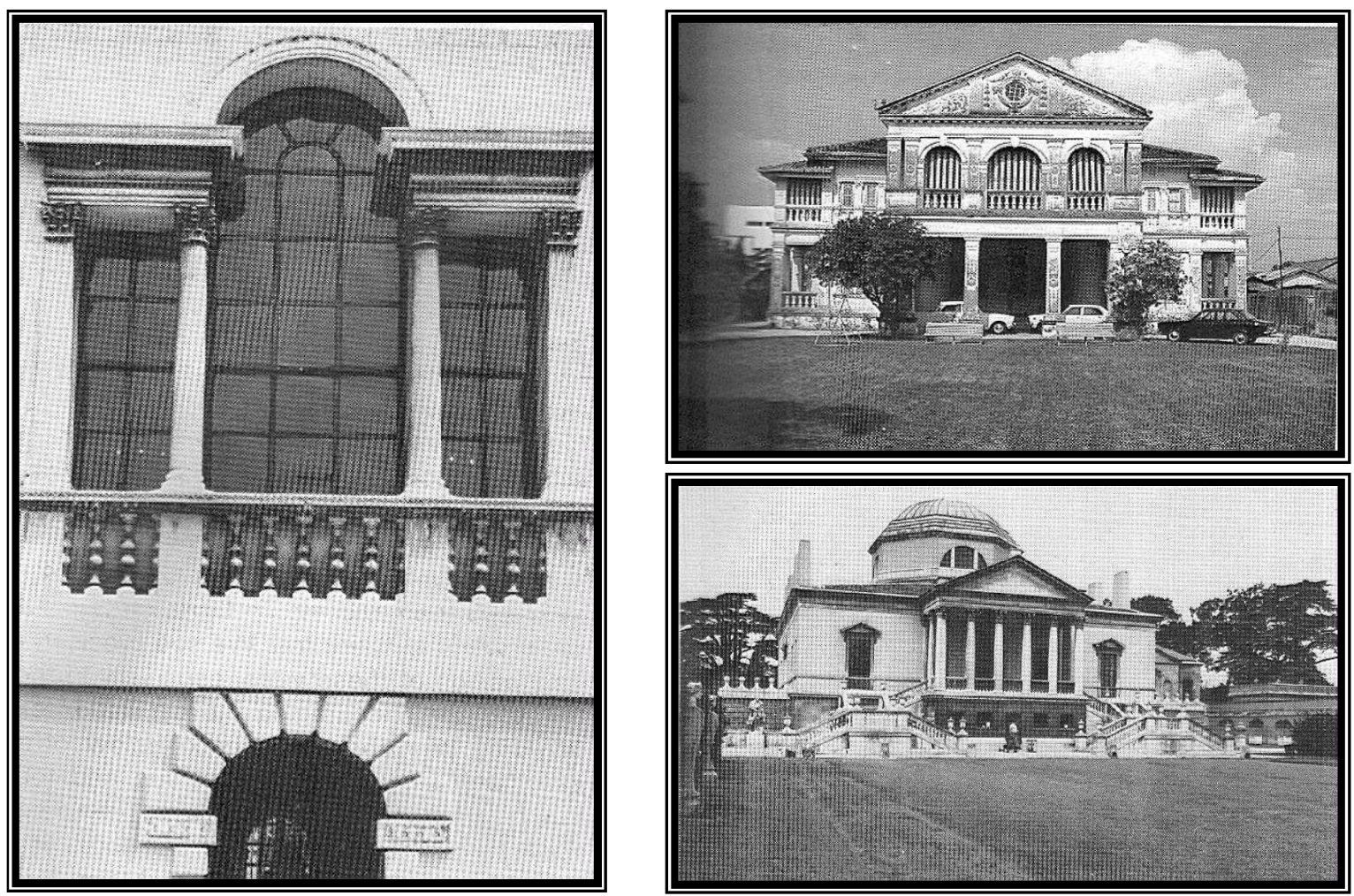

52

الثكل رقم (2) التعديلات ضمن فيلات جوج تاون في ماليزيا عن نمط فيلا بلاليو الايطالين]2 ص 158] 


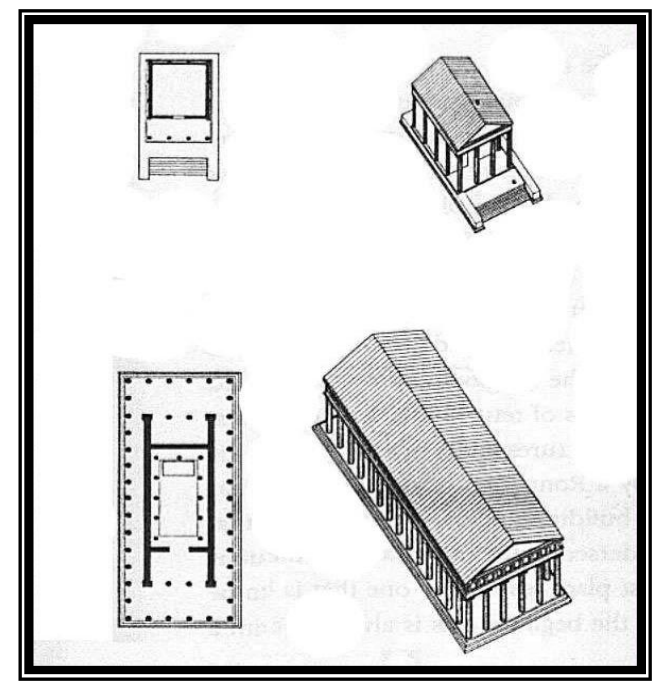

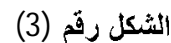

تطور أنموذج المعبد التقليدي

عن نمط مسكن (The Classical Temple)

الميكارون (Megaron House)

[44-42 3]

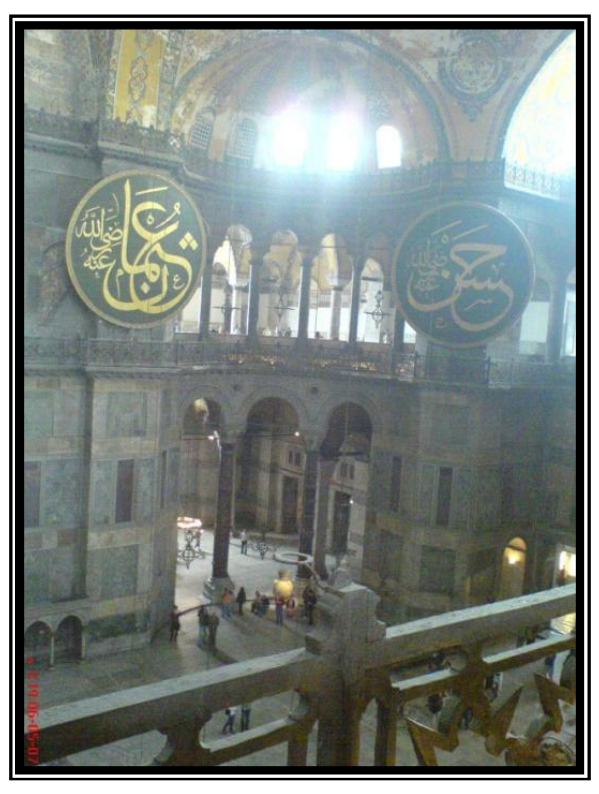

الثكل رقم (5) تكييف مبنى كنيسة آبا صوفيا S.Sophia واثراص الثُمس والمآذناتصوير الباحث في زيازة [2007/5/12 [يانية بتأريخ

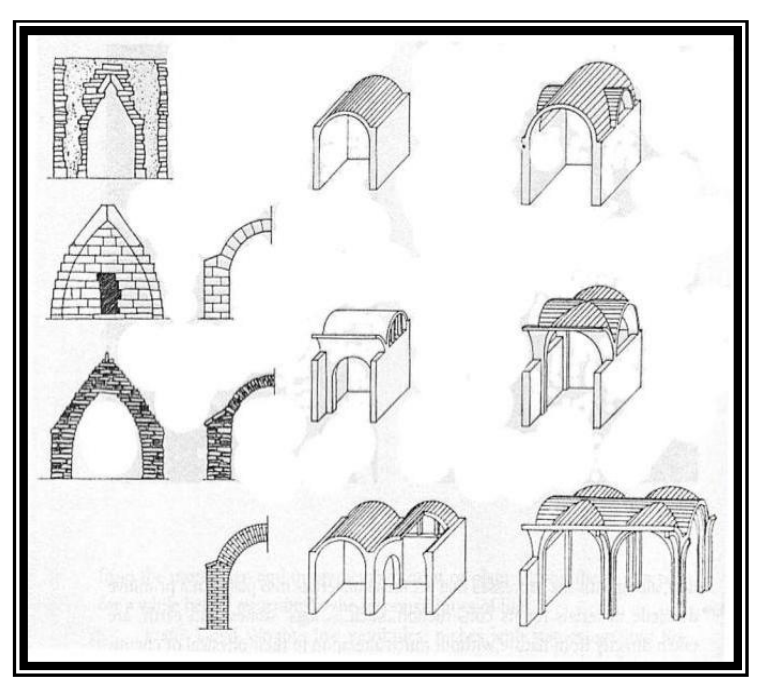

الثكل رثم (4)

تكيبف بعض التماذج والأنَكال البنائية

والإشائية وتطور ه] 3 ص 61 -60]
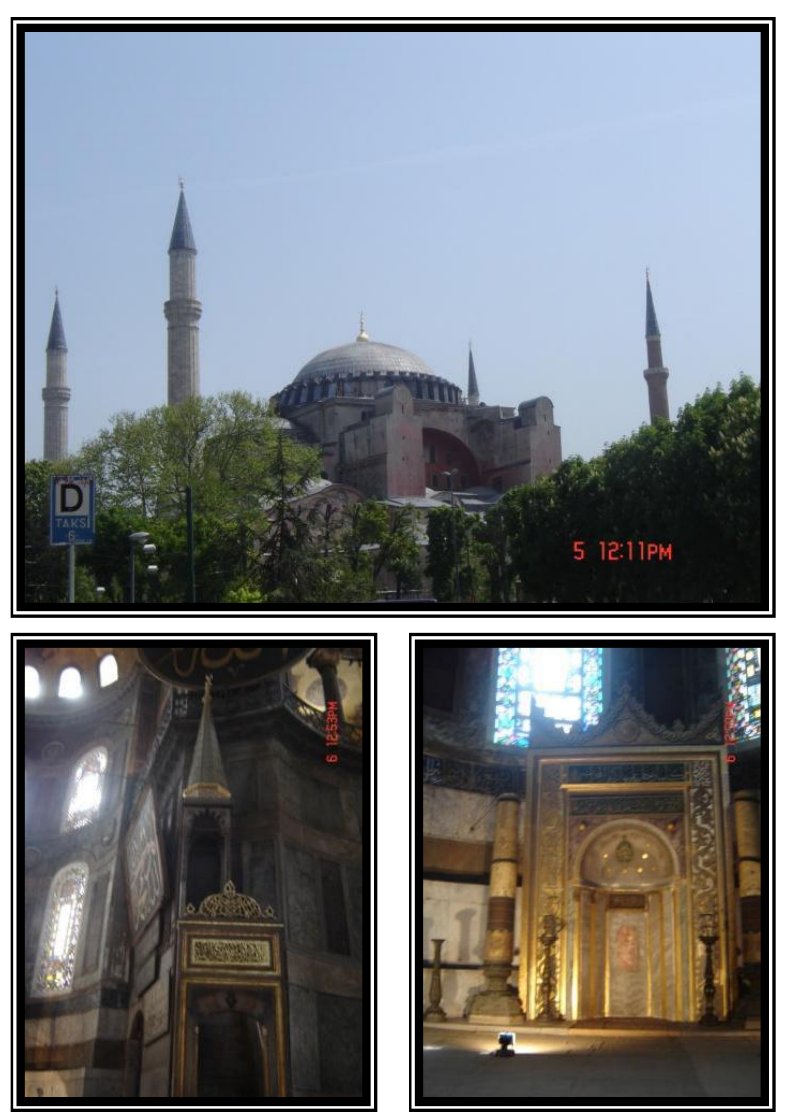

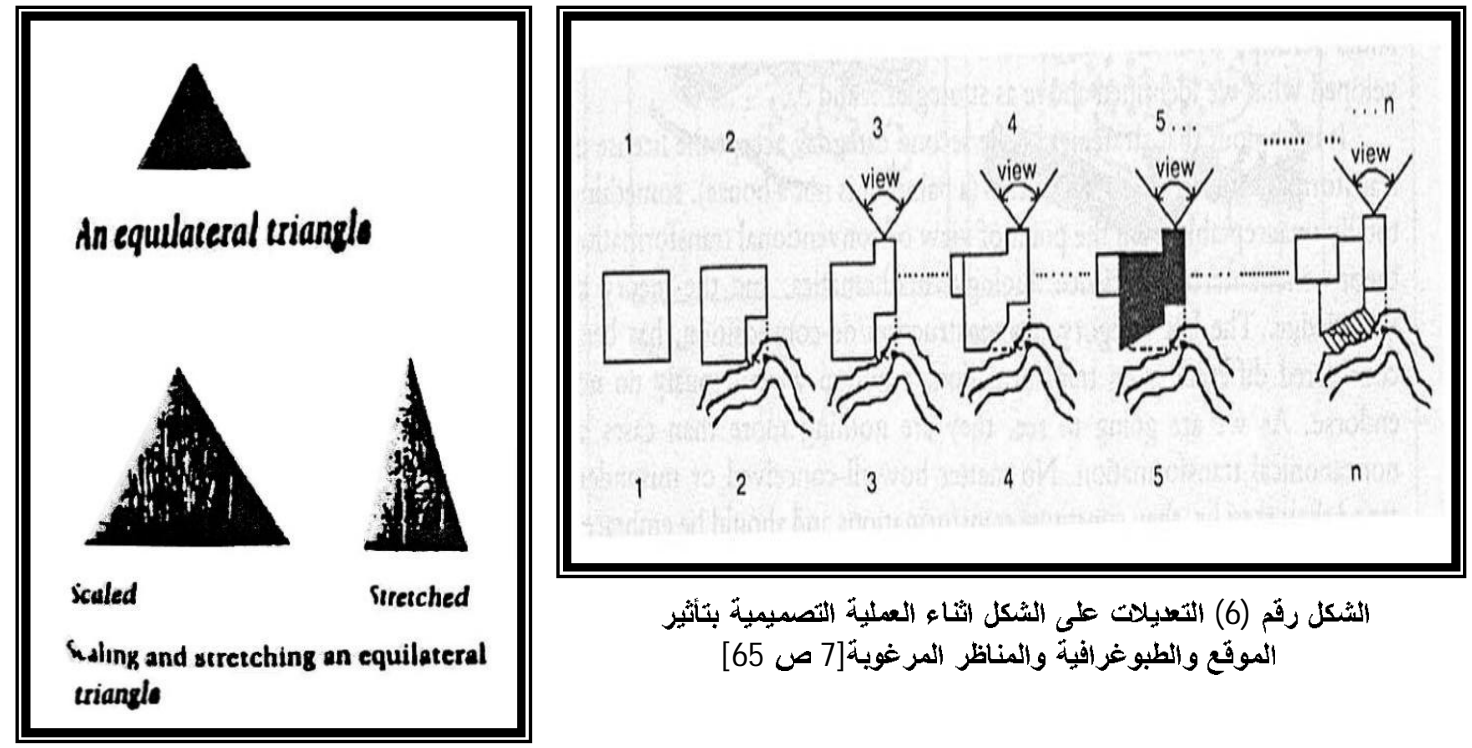

الثكل رقم (6) التعليلات على الثنكل الثناء العملية التصميمية بتأثير

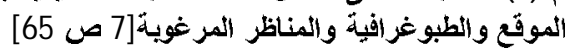

الثكل رقم (7) التحولات المحافظة أو المقفلة،

كمثال تحولات المقياس على المثلث المتساوي المثلي

أنساتين عل

[113 16 ]

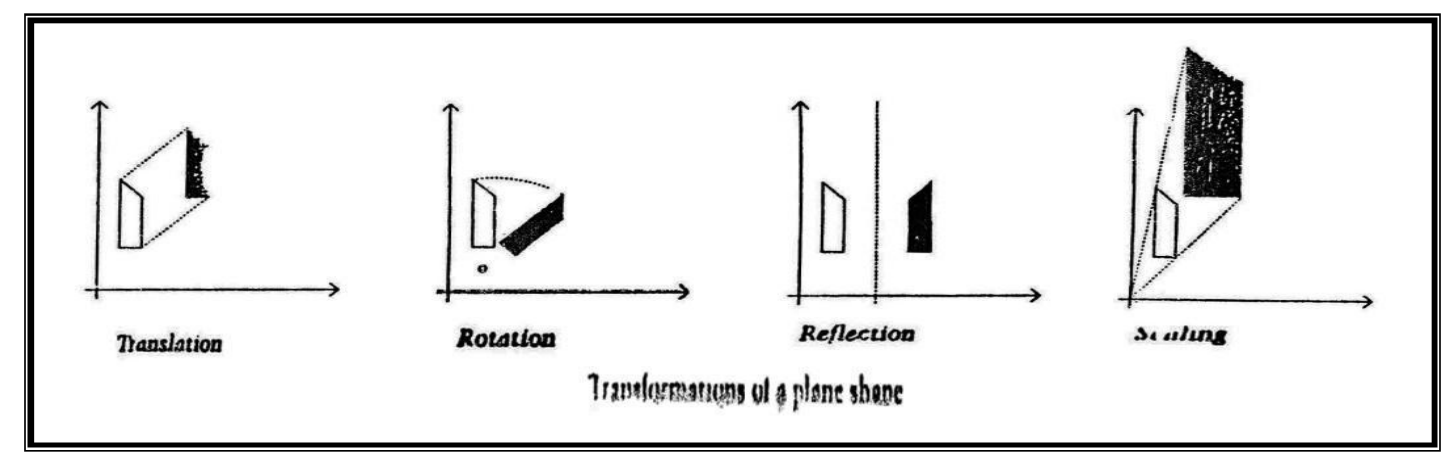

الشكل رقم (8) التحولات منساوية القياس (الازاحة، الثنويز، الانعكاس، المقياس) [10 ص 114]

الثكل رتم (9) أمثلّة لتحولات

الاضاقة والطرح [ [ 17 ص 8]

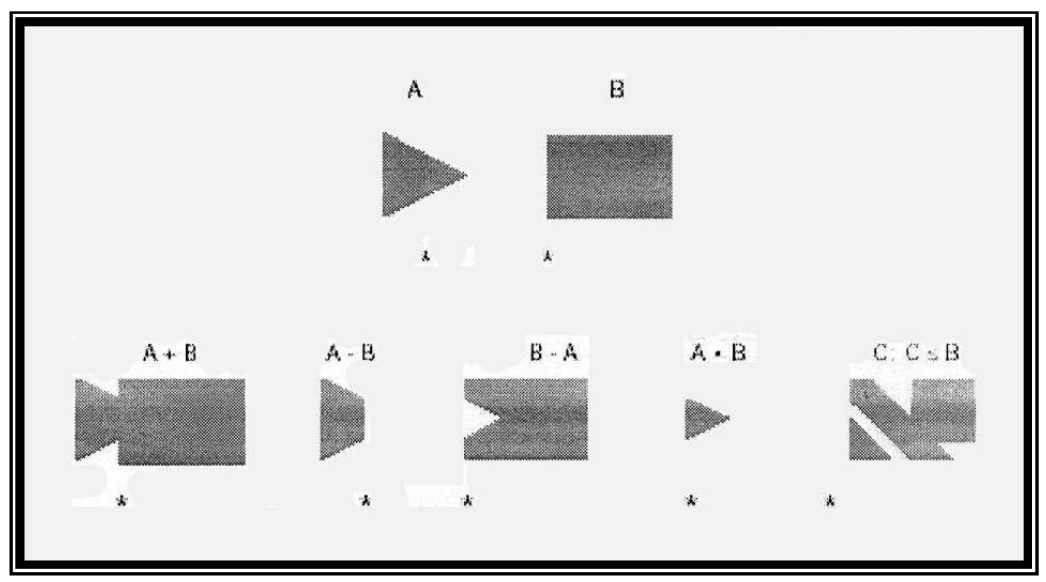




\begin{tabular}{llll} 
Al-Rafidain Engineering & Vol.18 & No.3 & June 2010 \\
\hline
\end{tabular}

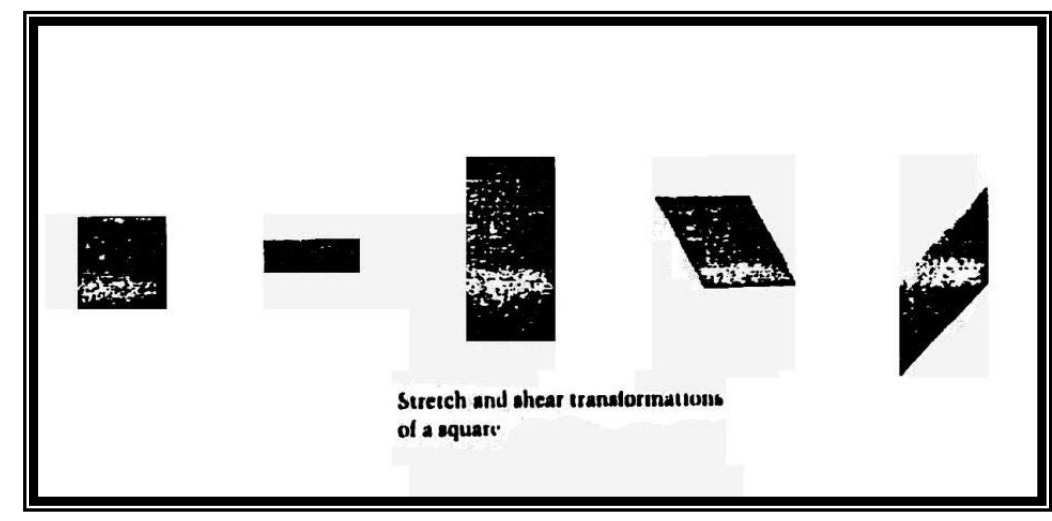

الثكل رتم (10) تحولات المد

Shear والثص كtretching

16] ضمن التحولات غير المقفلة

ص ص

تم اجراء البحث في كلية الهندة - جامعة الموصل 